\title{
Multicriteria Decisions in Urban Energy System Planning: A Review
}

\author{
Sébastien Cajot ${ }^{1,2 \star}$, Atom Mirakyan ${ }^{3}$, Andreas Koch ${ }^{1}$ and François Maréchal ${ }^{2}$ \\ ${ }^{1}$ European Institute for Energy Research, Karlsruhe, Germany, ${ }^{2}$ Industrial Process and Energy Systems Engineering Group, \\ École Polytechnique Fédérale de Lausanne, Lausanne, Switzerland, ${ }^{3}$ Energy Economics and Planning Department, \\ Lahmeyer International, Bad Vilbel, Germany
}

OPEN ACCESS

Edited by:

Gurkan Sin,

Technical University of

Denmark, Denmark

Reviewed by:

Miguel Mauricio-Iglesias, Universidade de Santiago de

Compostela, Spain Franjo Cecelja,

University of Surrey, United Kingdom

*Correspondence: Sébastien Cajot sebastien.cajot@alumni.epfl.ch

Specialty section: This article was submitted to Process and Energy Systems Engineering,

a section of the journal Frontiers in Energy Research

Received: 06 December 2016

Accepted: 04 May 2017

Published: 30 May 2017

Citation:

Cajot S, Mirakyan A, Koch A and

Maréchal F (2017) Multicriteria Decisions in Urban Energy System

Planning: A Review.

Front. Energy Res. 5:10. doi: 10.3389/fenrg.2017.00010
Urban energy system planning (UESP) is a topic of growing concern for cities in deregulated energy markets, which plan to decrease energy demand, reduce their dependency on fossil fuels, and increase the share of renewable energy sources. UESP being a highly multisectoral and multi-actor task, multicriteria decision analysis (MCDA) methods are frequently used in the decision processes. These methods may provide support in organizing and identifying solutions to problems with conflicting objectives. However, knowing which method to use is generally not straightforward, as the appropriateness of a method or combination of methods depends on the decision problem's context. Therefore, this article reviewed scientific papers to characterize and analyze MCDA problems and methods in the context of UESP. The review systematically explores issues such as the scope of the problems, the alternatives and criteria considered, the expected decision outcomes, the decision analysis methods and the rationales for selecting and combining them, and the role of values in driving the decision problems. The final outcome is a synthesis of the data and insights obtained, which may help potential users identify appropriate decision analysis methods based on given problem characteristics.

Keywords: multicriteria decision analysis, decision support, optimization, urban planning, energy planning, urban energy system

\section{INTRODUCTION}

In the past decades, the energy sector has undergone profound changes and is currently facing new challenges. Concerns for climate change, linked to GHG emissions and fossil fuel consumption, have led many countries to actively decrease their energy demand, reduce dependency on fossil fuels, and increase the share of decentralized and renewable energy (IEA, 2008). While the deregulation of the energy market in many countries has offered new opportunities in achieving this transition, it also increased the complexity and scope of energy planning (Makkonen, 2005). In this context, cities play an important role, by reshaping the urban form and their energy infrastructure. Since the rise of environmental and social concerns in the end of the previous century (Rittel and Webber, 1973; UNCED, 1992), the field of urban planning has opened up to include these issues. Thus, urban planners play a considerable role, as they must mediate and account for the many interests at stake when making decisions (Teriman et al., 2010). While it has been demonstrated that the lack of analytical support may lead to the use of simplified and contradictory decision rules (Keeney, 1992; Pedrycz et al., 2011), monocriterion approaches are most likely suboptimal when considering a wider range of objectives and attributes and thus support longterm sustainable development only partially (Mirakyan and De Guio, 2013a). Several methods focusing essentially on monetary aspects, such as cost-benefit analysis, cost-effectiveness analysis, or financial analysis, have been qualified as "reductionist" techniques for failing to capture the multiple 
facets of a problem (Dodgson et al., 2009; Browne et al., 2010). For these reasons, multicriteria decision analysis (MCDA) methods have become increasingly popular in the field of energy planning (Pohekar and Ramachandran, 2004; Zhou et al., 2006; Løken, 2007; Wang et al., 2009), enabling users to better understand the decision problem they face, negotiate, quantify and communicate preferences, and make decisions more explicitly and rationally (Pohekar and Ramachandran, 2004; Ghafghazi et al., 2010).

Several reviews of MCDA methods have been realized, some with more specific focus on energy-related problems. The initial review of MCDA applications in energy and environmental studies by Huang et al. (1995) was later updated by Zhou et al. (2006), who underlined the important increase in applications. Pohekar and Ramachandran (2004) classified and reviewed more than 90 papers on MCDA applications to sustainable energy planning, aiming to highlight the suitability of methods to different application areas, namely "renewable energy planning, energy resource allocation, building energy management, transportation energy management, planning for energy projects, electric utility planning and other miscellaneous areas." Polatidis et al. (2006) proposed a framework to help select suited MCDA methods for decisions related to renewable energy sources (RES). Løken (2007) discusses and classifies energy planning studies, which adopted various MCDA methods including value measurement models, goal, aspiration and reference models, and outranking models. Wang et al. (2009) reviewed the most frequent criteria used in MCDA for energy system sustainability, as well as corresponding methods for criteria weighting, evaluation, and aggregation. Dodgson et al. (2009) provide an overview of MCDA techniques, as well as practical guidelines for their application in various areas of government decision-making, including energy issues. Strantzali and Aravossis (2016) reviewed papers that applied various decision support methods (MCDA, cost-benefit analysis, and life cycle analysis) to renewable energy investment studies, classifying them by year, application area, and geographic distribution. Greco et al. (2016) present a historical context for MCDA, as well as in-depth descriptions of outranking methods, multiattribute utility and value theory methods, non-classical methods to cope with uncertainties and fuzzy measures, and multiobjective optimization methods.

Given the current needs for urban areas and their energy systems to help solve the climate and energy challenges discussed above, the present review examines more specifically the studies making use of MCDA in this area. Several lacks identified in the literature have in particular motivated this article and its focus on the urban scale. First, it has been noted how MCDA studies so far have rather focused on the macro scale (national and regional) or the micro scale (single building or user) and avoided the intermediate urban and neighborhood scales (Makkonen, 2005; Løken, 2007). In addition, the importance of these local scales for energy planning has become a central topic of research, as will be elaborated in Section "Urban Energy System Planning." Løken (2007) also observed a lack of studies covering simultaneously multiple sectors and energy carriers, advocating more integrated approaches. More generally, he and Hobbs and Horn (1997) also advocated the combination of multiple MCDA methods, as the choice of a method strongly influences the decision outcome.
Stemming from these lacks, as well as other open issues impacting decision outcomes (Section "Review Questions"), this review investigated the literature on UESP involving MCDA, with the aim of achieving the two following objectives:

1. To characterize and classify the nature and types of MCDA problems related specifically to UESP, investigating aspects such as the problem's scope (localization, spatial scales, temporal scales, topics, and planning focus), alternative generation methods, criteria used, decision problematic, and planning driver.

2. To survey the MCDA methods (and supporting methods) used to solve these problems, the reasons for selecting them, and when applicable, the rationales for combining them.

After addressing these objectives by analyzing the reviewed papers, a synthesis is performed by combining the data into a multicriteria decision support framework to facilitate the choice of appropriate MCDA methods in the area of UESP. As a simple and intuitive way to explore multivariate data, parallel coordinates are adopted to visualize and interactively select relevant methods. In fact, several authors previously noted that choosing an appropriate MCDA method was a MCDA problem in itself (Al-Shemmeri et al., 1997; Løken, 2007; Ghafghazi et al., 2010). However, Guitouni and Martel (1998) recommend avoiding the "vicious circle" of using an MCDA method to choose an MCDA method, advocating instead the definition of methodological principles and decision-making situation typologies to help choose appropriate methods. A review-based approach as proposed here, which characterizes the decision problems and corresponding decision support methods, therefore offers a framework to help choose methods according to various problem characteristics.

The present review can be useful for both researchers in the fields of urban planning and decision science and to practitioners. To the latter, it offers an overview of existing methods and a means to identify those most suited to their problems and decision contexts. To the former, several research priorities and topics, based on the findings, are addressed and proposed in the concluding section.

The article is structured as follows. First, core concepts and definitions used throughout the article are presented, as well as the review methodology, and describing in particular the review questions (Section "Definitions and Methodology"). Next, the results gathered from the review of all articles are analyzed, and a synthesis is performed by combining the data into a decision support framework (Section "Results"). Main insights and findings are discussed (Section "Discussion"), before concluding the article with some general outlooks and critics of the work (Section “Conclusion”).

\section{DEFINITIONS AND METHODOLOGY}

\section{Definitions}

This article links the fields of MCDA and urban and energy planning. Basic definitions from these fields, which will be used throughout the article, are clarified in this section. 


\section{Multicriteria Decision Analysis}

Multicriteria decision analysis allows to organize and structure complex decision problems characterized by multiple, often conflicting objectives. Several scholars in the field of MCDA have stressed that MCDA should not be mistaken for decisionmaking techniques, but rather techniques for analysis and aid (Keeney, 1982; Roy, 1996; Belton and Stewart, 2002). Keeney (1982) for example wrote that "decision analysis will not solve a decision problem, nor is it intended to." Belton and Stewart (2002) stated that the main goal of MCDA should be "to facilitate decision-makers' (DM) learning about and understanding of the problem faced, about their own, other parties' and organizational priorities, values and objectives and through exploring these in the context of the problem to guide them in identifying a preferred course of action." As discussed in the studies by Dodgson et al. (2009) and Wang et al. (2009), from the definition of the problem to the desired decision analysis outcome, four mains steps should be followed (Figure 1). This process is not necessarily sequential and may have iterations (Guitouni and Martel, 1998).

A multicriteria decision problem thus essentially consists of a set of alternatives that are evaluated on the basis of conflicting and incommensurate criteria, according to the DM's preferences (Malczewski and Rinner, 2015). Therefore, the main elements of any multicriteria decision problem include values, alternatives, criteria and their weighting, and DMs.

Values can be defined as principles or beliefs, held by individuals or groups, which reflect their conception of what are good or desirable states or behaviors (Connelly and Richardson, 2005; Balint et al., 2011). In this sense, they rationalize actions and guide the selection or evaluation of behaviors and events. According to the study by Keeney (1992), values are typically indicated in seven different forms (ethics, traits, characteristics, guidelines, priorities, value tradeoffs, and attitude toward risk). To be of use in decision-making, they are made explicit through associated statements, criteria, objectives, and weights. Values are rather ends in given time horizon and should not be confused with means. As proposed in the study by Keeney et al. (1987), a "value tree" can be established to elicit the values of stakeholders and derive an organized hierarchy of corresponding criteria that achieve or describe the given values.

An alternative is a means toward the satisfaction of the values and criteria. In some cases, it is the aim of MCDA to short list a wide range of existing alternatives and, in others, the identification of alternatives is itself a necessary and active process (Dodgson et al., 2009). As suggested by Keeney (1992), alternatives are only important in the way that they satisfy the values (and the criteria involved), and their identification should therefore be driven by these values. Alternatives can be generated either automatically

Context, values
and problem
definition $\rightarrow \begin{gathered}\text { Identify } \\ \text { alternatives }\end{gathered} \overbrace{\begin{array}{c}\text { Identify } \\ \text { criteria }\end{array}}^{3} \begin{gathered}4 \\ \begin{array}{c}\text { Define } \\ \text { weights }\end{array}\end{gathered}$

FIGURE 1 | Main steps involved in multicriteria decision analysis. (as often the case in multiobjective optimization) or manually (Pedrycz et al., 2011).

Although there is no standard definition of the expression "criteria" (Nijkamp et al., 1990), generally speaking, a criterion represents a standard of judgment to test the acceptability of an alternative (Pedrycz et al., 2011). In multicriteria literature, it is used to describe two distinct concepts: objectives and attributes. Objectives indicate the desired direction toward which a DM wishes to move (for example, minimum cost or maximum energy efficiency) (Pedrycz et al., 2011). We can distinguish objectives from goals, which represent a threshold or target level to reach, in terms of a specific state in space and time, while the objective gives the desired direction (Hwang and Masud, 1979). Attributes are a set of characteristics chosen by DMs that measure the performance of an alternative (e.g., how it impacts employment, quality of life, environmental parameters) (Hwang and Masud, 1979; Pedrycz et al., 2011). Weights are determined to indicate the relative importance or preference of criteria (Wang et al., 2009).

The DM is but one among several types of actors in a decision process. Roy (1996) describes three main types of actors: stakeholders, third parties, and analysts. The former are those who have an important interest in the decision and directly intervene in the decision process. They consist either of individuals, a clearly defined group of individuals (an elected body, a panel of experts, etc.), or a group with less well-defined boundaries (a lobby, public opinion, etc.). Usually, the objectives and values of the different stakeholders are diverse and conflicting. Because the decision aid cannot simultaneously benefit all stakeholders comprehensively, one stakeholder is generally identified as the DM. The second type of actors are referred to as third parties, as they do not actively take part in the decision process, but are affected by its consequences, and thus whose preferences must be taken into account (typically the citizens, end-users, consumers, etc.). A third type of actor is the analyst, who plays a role in supporting the DM. In some cases, the DMs may develop the decision aid themselves, but generally this task is performed by an analyst different from the DM. This is in particular the case when the DM does not possess the technical or methodological background, or when an external party is desired to ensure a neutral and more objective approach. In summary, stakeholders are the actors who actively take part in the decision process and include the DM. These can be assisted by an analyst whose role is to provide methodological support to help answer questions posed by a stakeholder in a decision process. This support must take into account the interests of not only the stakeholders, but also third parties who are affected by the decision.

Rationales for using MCDA in energy planning have been discussed and compared to other decision support methods (costbenefit approach, cost-effectiveness approach, energy ecological footprint, etc.) or simply to informal judgment unsupported by such methods (Dodgson et al., 2009; Wang et al., 2011). The main arguments in favor of MCDA from the studies by Pohekar and Ramachandran (2004), Dodgson et al. (2009), Browne et al. (2010), Coelho et al. (2010), Ghafghazi et al. (2010), and Wang et al. (2011) can be summarized as follows:

- Useful to resolve conflicting interests and reach compromises

- Transparent, explicit, and flexible 
- Promotes public participation in decision-making processes

- Can be process - rather than results - oriented to favor understanding of the problem

- Synthesizes multiple aspects in a single decision output

- Facilitates multidisciplinarity

- Can represent the preferences of multiple stakeholders by varying weights

- Can analyze incommensurable or uncertain criteria

- Can handle and aggregate qualitative and quantitative information

- Can complement a reductionist approach by providing a more holistic approach

Browne et al. (2010) nevertheless point out two key drawbacks of MCDA in energy planning, namely the dependency on subjective judgment in qualitative approaches and the difficulty to quantify environmental or social impacts. MCDA has also been criticized for providing inconsistent results, being highly dependent on method choice and subjective stakeholder preferences (Guitouni and Martel, 1998).

\section{Urban Energy System Planning}

Energy planning is a complex issue for involving not only multiple criteria but also for spanning across multiple scales, from the building scale up to national or international scales (Wierzbicki et al., 2000; Thery and Zarate, 2009; Prasad et al., 2014). However, the urban scale has received particular attention in the past years regarding energy issues, as cities are acknowledged to play an important role in mitigating climate change. The International Energy Agency estimates that cities represent two-thirds of the world's energy consumption and GHG emitters and could therefore notably curtail climate change impacts through local authority engagement (IEA, 2008). The Intergovernmental Panel on Climate Change has recently noted urban planning and other city scale interventions among the key measures for climate change mitigation (IPCC, 2014). The United Nations similarly advocates municipal-led energy conservation and carbon emission reduction plans (Habitat-Iclei, 2009). Cities themselves have recognized their strengths, as noticeable through the Aalborg charter signatories (Aalborg Charter, 1994), who declared "that the city or town is both the largest unit capable of initially addressing the many urban (...) natural resource and environmental imbalances (...) and the smallest scale at which problems can be meaningfully resolved in an integrated, holistic and sustainable fashion." The "Covenant of Mayors" (Covenant of Mayors, 2016) is a city-based European initiative, which aims to help cities achieve the EU's climate targets (EC, 2007, 2014), by fostering exchange of experience. The network of megacities C40 also acknowledges, through various studies, the important role cities play in addressing climate change (C40, Arup, 2014; C40, Arup, UCL, 2015).

This trend for planning energy at the urban scale is further supported by research in various fields. The urban level is believed to offer a more direct and concrete space to act regarding energy consumption and supply, allowing for effective adaptation of policy measures to local specificities (Chapuis et al., 2010; Keirstead and Schulz, 2010; Caputo and
Pasetti, 2015). St. Denis and Parker (2009) identified that given recent technological advancement and better access to local knowledge, communities have become more active in planning their own energy systems. They identified several advantages at this local scale, including increased social input and participation of locals, more agile responses to opportunities and threats, more personal investment and interest of actors, and a clearer link between local consumption and generation. On the other hand, the more localized scale of the individual building scale is found less effective than wider district or urban scales, neglecting possible benefits of considering multiple buildings on the demand side (e.g., by taking shading into account when planning the building stock) and on the supply side (e.g., enabling economies of scale or energy-efficient centralized systems) (Ratti et al., 2005; Koch, 2009; Zanon and Verones, 2013; Immendoerfer et al., 2014; Petersen, 2016). As a means to effectively perform this "upscaling" (UN-Habitat, 2009; Gossop, 2011; Zanon and Verones, 2013; Cajot et al., 2015; Strasser, 2015) have argued that energy issues should integrate existing urban planning processes. A survey from UP-RES (2011) made clear the interest and need from building scale specialists to access training regarding the energy solutions on the urban scale.

The planning of energy infrastructure is not essentially new to the wide range of urban activities; however, its handling by means of integrated, cross-sector, and multiactor approaches is relatively recent. Many cities are struggling to develop new methods to successfully bring together energy issues in the framework of urban planning procedures (Zanon and Verones, 2013; Immendoerfer et al., 2014; Strasser, 2015). Because of the novelty of such approaches, the term of urban energy system planning itself can be subject to debate and is worth clarifying. Based on a compilation of fragmented definitions of its subterms from literature, we put forward a synthetic definition of UESP, in an attempt to facilitate and improve the discussion on this emerging field.

- UES is defined by Keirstead et al. (2012) as "the combined processes of acquiring and using energy to satisfy the energy service demands of a given urban area."

- Hopkins (2001) refers to urban planning as "intentional interventions in the urban development process, usually by local government," and where "the term 'planning' (...) subsumes a variety of mechanisms that are in fact quite distinct: regulation, collective choice, organizational design, market correction, citizen participation, and public sector action." The concept of urban planning, previously confined to the task of designing a physical and spatial framework, has grown to serve also a more strategic function, defining and influencing the development of society (Albers, 1986). As such, urban planning is as much concerned with the spatial organization and interrelations between urban components and activities, as it is with the strategic, intersectoral, and more abstract planning of a city's development, translating visions into goals, actions, and investment priorities (Healey, 2004; UN-Habitat, 2009). 
- Model-based energy planning in cities or territories is defined by Mirakyan and De Guio (2013a) as "an approach to find environmentally friendly, institutionally sound, social acceptable and cost-effective solutions of the best mix of energy supply and demand options for a defined area to support long-term regional sustainable development. It is a transparent and participatory planning process, an opportunity for planners to present complex, uncertain issues in a structured, holistic and transparent way, for interested parties to review, understand and support the planning decisions."

On the basis of the above, we define UESP as the inclusion of energy issues (related to the acquisition and use of energy) in the processes of urban planning (which strategically and spatially organize the development of a city) to find environmentally friendly, institutionally sound, socially acceptable, and costeffective solutions to satisfy the demands of an urban area.

\section{Review Methodology and Scope}

The review presented hereafter analyzed papers obtained by searching the Scopus database. The search included papers ranging back as far as the database allowed (the oldest paper surveyed going back to 1990), to the date of writing of the present article (the most recent paper being from 2016). The query performed aimed at identifying all papers dealing with MCDA in urban and energy planning by searching titles, abstracts, and keywords. Search terms were selected according to the following aspects. Literature on MCDA frequently replaces the latter term with "making" or "aid." To avoid missing any entries, only the key words "multi criteria" were employed. The keywords "energy," "planning," and "decision" were included to narrow the search to the topic of interest. "Urban planning" can be interchangeably referred to as "city planning" or "town planning." The latter did not influence the search results and was not included in the query. Furthermore, urban planning spans across several administrative scales and therefore the keywords "district" and "neighborhood" were included to reflect this.

After testing the sensitivity of the different key words and of logical operators AND/OR, the final query included all studies published in both journals and conference proceedings, leading to 127 papers. Papers were only kept for the review if they explicitly discussed or applied MCDA in urban or urbanrelated contexts. From the 127 papers identified, 23 were thus discarded as being off-topic and 17 were unavailable, leaving 87 reviewable papers. Two of the papers included 2 distinct MCDA studies. The identified sample of 89 MCDA studies is deemed sufficient to address the present review's objectives (Section "Introduction").

The relevant studies applying MCDA for UESP were found in a total of 58 different journals and conference proceedings and are well dispersed across the various sources. The journal energy contains the majority of studies (10), followed by Applied Energy and Energy Policy (4 studies each).

Figure 2 reveals the increasing popularity in MCDA applications in UESP, which took off in the 2000s, with an average of 1.7 papers published per year until 2010 and an average of around 11 papers per year since.

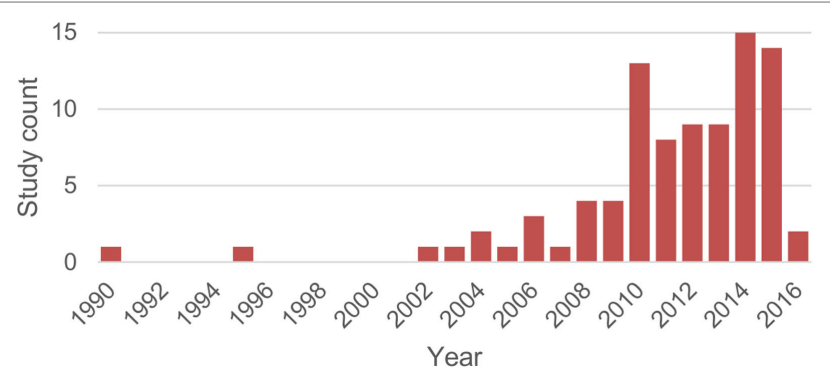

FIGURE 2 | Distribution of publication dates for the 87 papers reviewed involving multicriteria decision analysis in urban energy system planning

\section{Review Questions}

Seven review questions were defined to address the two review objectives stated in the introduction. The first objective of characterizing UESP problems was achieved by analyzing the following five questions for each study:

(i) What was the problem's scope (including geographical location, physical scale, temporal scale, topic, and planning focus)?

(ii) How many alternatives were considered, and how were they elicited?

(iii) How many criteria were used, and how were they selected?

(iv) What was the expected decision outcome or problematic?

(v) Was the problem driven by values or by alternatives?

The second objective of characterizing the MCDA methods was done by exploring the following two questions:

(i) How many MCDA and supporting methods were adopted, which ones, and why were they chosen?

(ii) Which methods were combined, and for what purpose?

Each question is further described in the following sections.

\section{Problem Scope}

In each reviewed study, the general scope of the problem was hereby investigated, considering the geographical location in which the problem was set (classified by continent), the physical scales bounding the problem (whether the focus of the planning was set on the building, neighborhood, city, regional, state, or country scale), and the temporal scale covered by the problem (noting any temporal horizon considered by the authors in their study). The different studies were also classified according to topic and planning focus. Concerning the topics, six broad themes were found sufficient to cover the extent of the reviewed papers, as follows: (1) heating and cooling, (2) power, (3) mobility, (4) environment, (5) waste, and (6) water/wastewater. The papers were further classified according to their planning focus as follows:

a. System specific planning: when only a subpart of the UES is considered, e.g., heating system, electrical system, demand side analysis in residential sector

b. Integrated or master planning: when different energy carriers, sectors, or demand and supply systems are considered 
c. Operative planning and management: when the main focus is not on long-term system design and investment, but rather on operative aspects, e.g., optimization of energy supply or energy use

\section{Alternatives}

This review question counted the number of alternatives analyzed by each study and the methods used to identify them. Keeney (1992) emphasizes the importance of alternative creation, writing that it "may be more important to create alternatives than to evaluate readily available ones." He blames decision methodologies for often neglecting this aspect or inhibiting it. If many MCDA problems in literature may lead to believe that the typical application involves a predefined set of alternatives, this is often not the case (Belton and Stewart, 2002), and the more complex problems such as those found in UESP require careful thought in the structuring of the problem and identification of alternatives. For example, Feng and Lin (1999) point out the limitations of conventional approaches for generating new urban layout plans. They argue that the urban development process should begin with a systematic generation of physical layout alternatives, but deplore that conventional processes for generating alternatives are usually considered "a 'black box' inside which planners are subjective and alternatives are few." In response, they propose an optimization model to systematically elicit alternatives maximizing public comfort and convenience, with which they were able to identify four alternatives performing better than the original plan. Typical methodologies that can be used to support alternative generation are discussed in the study by Siebert and Keeney (2015), who review existing methodological approaches for creating alternatives (structured techniques, creativity techniques, value-focused thinking, etc.). Mirakyan and De Guio (2014) reviewed the main methods that can support alternative identification, including brainstorming, soft systems methodology; strengths, weaknesses, opportunities, and threats (SWOT) approach; Delphi; meansends objective network; and network of problems. They further proposed a methodology for finding innovative alternatives in planning, where common solutions may not be satisfactory, but where satisfying solutions are not obvious. Belton and Stewart (2002) present various methods for idea generation, some of which can help think about and identify alternatives. These include checklists to stimulate idea generation, alternative-based thinking methods, where users analyze and compare alternatives to stimulate the generation of new ones, and value-focused thinking using means-ends objective network, introduced by Keeney (1992), where value elicitation is performed prior to alternative identification. Despite the advancement of research in this field, the reviewed studies usually remained implicit or fairly superficial in describing how the alternatives were generated. In this context, the review distinguished the following cases for alternative generation: by the authors themselves, based on literature; by external experts or actors; by relying on heuristic approaches such as mathematical multiobjective optimization, systematic combinations, and enumeration; or simply externally defined (e.g., the evaluation of grant request submitted). When specified, any supporting method used by experts or actors was noted [including Geographic Information System (GIS) software, SWOT analysis, communities of practice ( $\mathrm{CoP})$, or interactive user selection].

\section{Criteria}

This question considered the number of criteria used in the analysis and any explicit references to their selection process. These approaches included author's judgment, literature or predefined sets of indicators, experts' recommendations, and, when specified, other supporting methods (Delphi, CoP), or any combination of these approaches.

\section{Decision Problematic}

The problem type, as posed in the study, was surveyed. This question is of particular interest in the field of MCDA and can even be considered as the first and most important step in MCDA (Chen, 2006): when addressing complex decision problems, analysts must initially consider what type of result or outcome is expected. Roy (1996) first used the term "problematic" to describe the main types of outcomes MCDA can provide. In this review, we investigated which problematics were adopted, based on the most relevant problematics proposed by Roy (1996) and Belton and Stewart (2002). According to their typologies (Figure 3), a MCDA approach can be applied to

- select or choose a "best" alternative, by reducing the set of alternatives to a smallest subset (choice problematic)

- help sort alternatives according to predefined categories, which shall help the DM know which treatment to give to the grouped alternatives (sorting problematic)

- rank the alternatives by order of preference, enabling the DM to think about the problem and discuss with all stakeholders (ranking problematic)

- choose a subset of alternatives, which can be combined and account for interactions and positive or negative synergies between them (portfolio problematic)

- search for, identify, or create new alternatives based on the insights gained from the MCDA process (design problematic)

- gain a greater understanding of the problem, in particular what may or may not be achievable (description problematic).

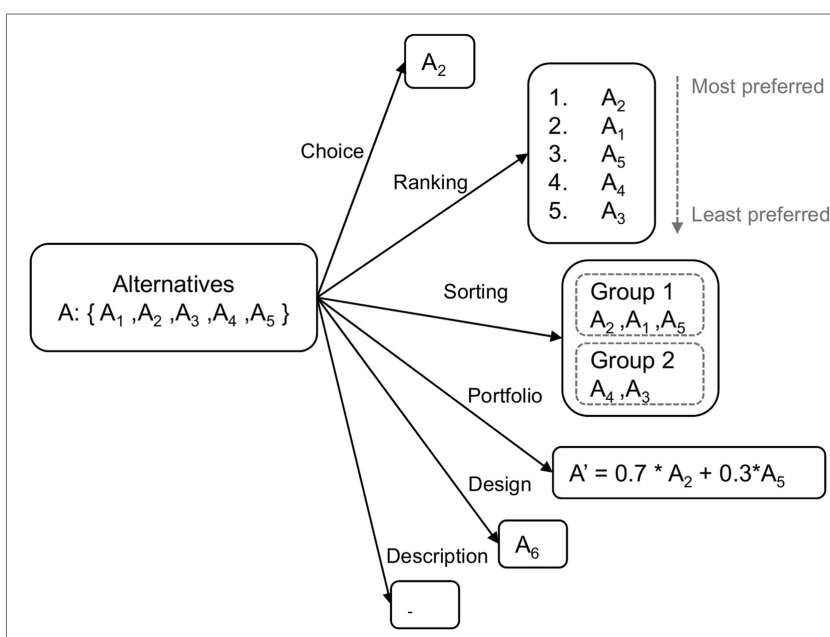

FIGURE 3 | Schematic overview of the multicriteria decision analysis problematics investigated in the review. Adapted from the studies by Belton and Stewart (2002) and Chen (2006). 
It should be noted that the delimitation between problematics is not always absolute and that a certain hierarchy can exist among them. For example, a first expected outcome may be ranking, followed by the choice of a single alternative. Similarly, portfolio can be considered a type of design problematic, in which alternatives are created by combining various subcomponents. In turn, the newly created portfolios can further be ranked, sorted, described, or chosen from. In the reviewed studies where multiple problematics concurred, the predominant one was retained, relying when possible on explicit statements from the authors.

Analysts must be aware of the type of results they aim to provide (a best single solution, a ranking of all solutions, the identification of original alternatives, etc.). Often, however, this appeared to be only implicitly considered or not considered at all. As the method used may constrain the type of result, this reinforces the argument of carefully identifying the expected decision outcome early in the decision process, to avoid the generation of undesired information and associated waste of time, effort, and cost.

\section{Planning Driver}

This question investigated the extent to which the planning problems were driven by values, rather than means or resources readily available. In the reviewed papers, values most often took the form of "characteristics of consequences that matter" stated in the introductory sections of the papers or as "priorities" and "value tradeoffs" when establishing criteria and weights.

This question is particularly relevant in the light of the recent changes in urban planning, which shifted from physical, expert-led approaches, to a wider, strategic, and collaborative form (Albers, 1986; Wachs, 2001; Scherrer, 2008). A wider scope, including in particular energy issues as well as public participation, implies that planners must cope with a wider range of values than previously, which poses a series of challenges such as their systematic incorporation in decision-making or gathering information about the values (O'Brien, 2003; Balint et al., 2011). Connelly and Richardson (2005) and O'Brien (2003) point out the general lack of explicit acknowledgment of-and distinction between-the different values that should influence and drive planning. According to them, omitting them, assuming values are known, or underestimating their diversity may lead to unacceptable outcomes. Keeney (1992) originally advocated "value-focused" thinking, as opposed to what can be called "alternative-focused" or "resource-focused" thinking. According to him, failing to elicit values before defining alternatives leads to a constrained vision of the problem, which "anchors the though process, stifling creativity and innovation." In addition, how alternatives are identified also directly influences how well the values shall be satisfied. Often, DMs do not spend enough effort on alternative creation, missing many alternatives, including important ones, hindering the achievement of the objectives (Siebert and Keeney, 2015). Exploring how values were involved in the reviewed studies, these were classified as either value driven or alternative driven, following loosely the framework from the study by Keeney (1992). This classification is not meant to be an absolute one, but rather to foster thinking about values in MCDA and how these could improve the final outcomes. Based solely on the reported elements in the final publication, and without the full knowledge of how the decision problem was actually addressed, the problem cannot easily be declared either purely value driven, or purely alternative driven. Instead, it lies within a continuum between both ends (Figure 4), depending on the reported information regarding values, and alternatives.

Several characteristics of value-driven approaches were used to evaluate the reviewed studies (Figure 4). As such, the studies that were more explicit in their elicitation of values, whose values in turn appeared to influence the identification of criteria and alternatives, and which considered a broader range of alternatives, or motivated the narrow set evaluated, were marked as value driven. Those who only moderately exposed the guiding values, or which values did not appear to influence the decision analysis, or which did not motivate the choice of alternatives were marked as alternative driven. To help in the classification, three types of alternative sets were used to describe the studies:

- Type 1: The study includes and compares different categories of alternatives (e.g., renewable energy technologies, refurbishment, funding options, spatial alternatives, information, and incentives)

\section{Value-driven}

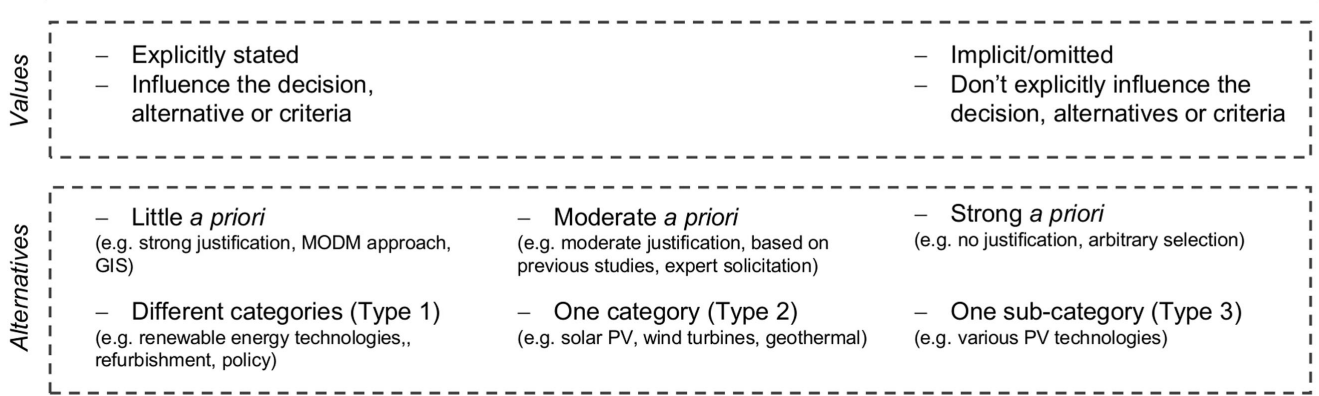

FIGURE 4 | Considered characteristics for classifying the studies as value or alternative driven. 
- Type 2: The study includes and compares alternatives from one category (e.g., different renewable technological alternatives, such as solar PV and wind, or different locations for a waste disposal)

- Type 3: The study includes and compares alternatives belonging to a single subcategory (e.g,. different solar PV cell types)

Three specific approaches for alternative generation (previously mentioned in Section "Alternatives") were also found to be particularly in line with value-driven thinking, as they enable a transparent and comprehensive way to identify alternatives, with little a priori in their construction. The first approach was multiobjective decision-making (MODM)-based heuristics, in which a wider range of alternatives are automatically generated by combining decision variables to best achieve predefined objectives, allowing more informed and more rational decisions (Cohon, 1978). Similarly, some GIS approaches also assumed a broad, continuous range of locations as possible solutions, as opposed to a comparison of a limited subset of preselected sites. Other systematic combinatorial approaches were found, in which theoretically all possible alternatives of a category were considered a priori. This was for example the case when enumerating all possible priority sequences for restoration of district heating pipe segments (Rochas et al., 2015). Finally, to complete the assessment of planning drivers, the stated rationales for selecting the set of alternatives, if available, were also used to classify the studies (e.g., authors who provided strong justifications for the choice of alternatives were more likely to be classified as value driven as if the alternatives were not justified or appeared to be selected arbitrarily).

It should be noted that the value- or alternative-driven nature of a problem should not necessarily be regarded as "good" or "bad." Indeed, the problem context may be simply conditioning an alternative-driven approach, as for example in the study by Hsueh and Yan (2011), where a method for comparing urban development projects that had applied for governmental grants is proposed. Similarly, some studies might not claim to find the best possible alternative to achieve a valued goal, but rather purposely aim to answer a more specific question about a given technology. This is for example the case of De Feo et al. (2008), who compares various coagulants for urban wastewater treatment.

\section{MCDA Methods}

This section aimed at identifying the MCDA methods, as well as the supporting methods, employed to address the different problems and the rationales behind their choice. There are many ways to categorize MCDA methods. In this study, they have been divided into five main groups, loosely based on classifications proposed by Belton and Stewart (2002), Zhou et al. (2006), Løken (2007), and Mardani et al. (2015): (1) value measurement models; (2) goal, aspiration, and reference level models; and (3) outranking models; (4) MODM; and (5) other methods. Value measurement models assign numerical scores to each alternative, by aggregating criteria and weights. Among the most common approaches include the weighted sum approach or analytical hierarchy process. The second group is often gathered under the expression goal programming, and a typical example is the Technique for Order Preference by Similarity to Ideal Solutions
(TOPSIS). The third group of outranking models distinguishes alternatives in a pairwise fashion for each criterion. This group is also referred to as the French school of MCDA methods, namely because of the pioneering work on the ELECTRE methods from Roy (1996). The fourth group included MODM methods, which relied either on linear programming techniques or multiobjective optimization heuristics such as evolutionary algorithms. This group also contained methods that were referred to as single-objective decision-making (SODM). Although in most cases, SODM considers just a single objective, providing a somewhat limited interpretation of a problem, their name can be in some cases misleading. SODM can indeed handle multicriteria aspects of a problem by resorting to various techniques (Savic, 2002). This can be achieved for example by aggregating various objectives in a single-objective function through a weighted sum (Yokoyama and Ito, 1995; Ma, 2012; Karmellos et al., 2015), by setting different constraints on criteria to evaluate trade offs with the objective, as in the $\varepsilon$-constraint method (Pérez-Fortes et al., 2012), or simply by varying the criteria being optimized and comparing outcomes (Ayoub et al., 2009). The fifth group included methods relying on fuzzy set theory (FST) and other methods developed more recently and referred to as decisionmaking aggregation methods in Mardani et al. (2015). FST can be either used to extend existing MCDA methods (Wang et al., 2009; Mardani et al., 2015) or used independently for criteria aggregation (Greco et al., 2016).

Several auxiliary methods are frequently found supporting the MCDA process. Referred to in this article as "supporting methods," these include for example the abovementioned FST, the Delphi method, SWOT analysis, GIS tools, and others.

Furthermore, the stated arguments for choosing a MCDA or their supporting methods were collected during the review. These arguments can be compared to the requirements and "quality factors" discussed in the study by Mirakyan and De Guio (2015) for choosing decision methods.

\section{Combination of MCDA Methods}

Also of interest regarding the MCDA methods was the combined use of methods and, most importantly, the rationale behind their selection and combination. Strantzali and Aravossis (2016) have recently pointed out the growing trend in combination and comparison of different methods' results. As mentioned in the section "Introduction," Løken (2007) and Hobbs and Horn (1997) have advocated using multiple MCDA methods to tackle a similar problem, as its solution may strongly depend on the method choice. Greene et al., 1989; Crump and Logan, 2008; and Mirakyan and De Guio, 2015 have discussed the various purposes and motivations for combining methods. Greene et al. (1989) initially noted five key purposes for mixing methods, which include triangulation, complementarity, development, initiation, and expansion (Table 1). The reviewed studies indeed often involved multiple methods, and the stated or inferred purposes were systematically monitored. As already encountered by Greene et al. (1989), the purpose stated by the authors may differ from the definitions proposed, in which case, for better coherence, the inferred purpose matching the definitions was noted. In several occurrences, several purposes were identified 
TABLE 1 | Purposes for combining multiple methods.

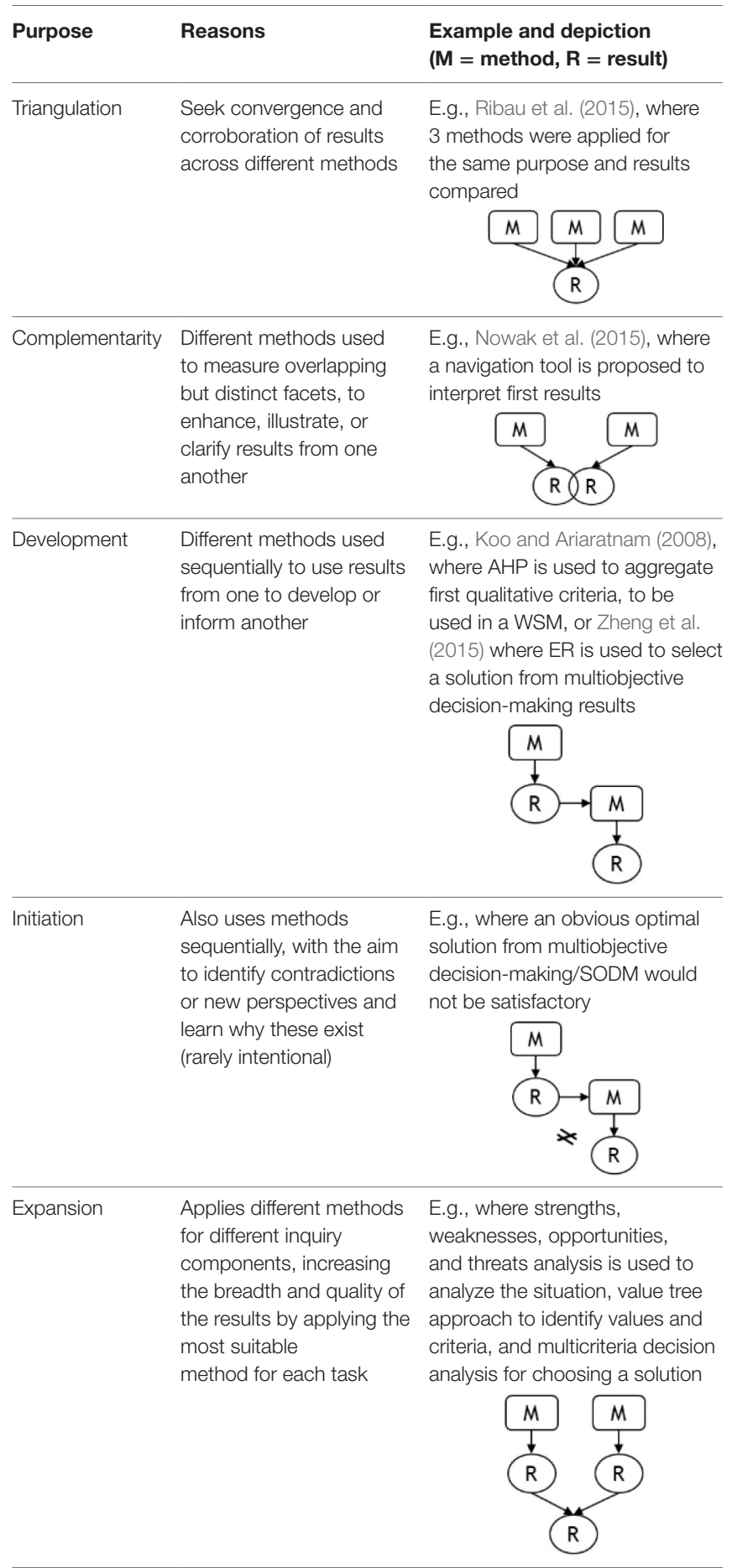

and noted as primary, secondary, and tertiary purpose, by order of importance in the study.

\section{RESULTS}

\section{Problem Scope}

This section presents the general results concerning the scope of the studies, as described above. A majority of papers were published by European (44 studies), Asian (23), and North American (15) institutions.

Regarding the scale at which the studies took place, a spread from country to building level was observed. Forty-eight studies covered the city scale, 14 the neighborhood, 10 the regional scale, 7 the building, 6 the country, and 2 the state. It should be noted that this spread appeared despite narrowing the search to the urban and neighborhood scales, illustrating the tendency of urban planning to also impinge upon broader and smaller scales.

Papers were grouped according to the typologies in Section "Problem Scope." The subtopics were tackled as follows: heating and cooling (43 studies), power (41 studies), and mobility or water/wastewater projects (20 studies each). This reflects the importance of the stakes associated with heating and cooling in buildings, the leading sector regarding GHG emissions, and primary energy use (IEA, 2008; Odyssee-Mure, 2015).

Regarding the planning focus of the studies, 63 were dealing with system specific aspects, whereas 18 handled the issues in an integrated way, considering multiple subtopics, energy carriers, or types of infrastructure, and 8 focused on operative planning aspects. The temporal horizons covered by each study are plotted in Figure 5, classified by planning focus. The sampled studies showed that planning projects that focused on specific aspects of the system coped on average with longer time horizons than projects considering the system as a whole (24 and 21 years, respectively). The operative planning and management studies considered time horizons of days to several years, on average considering the year as time perspective. These temporal horizons are closely in line with those of the planning tasks and decision-making levels discussed by Makkonen (2005) and Mirakyan and De Guio (2015), which distinguish strategic decisions (spanning over more than 10 years), tactical decisions (between 1 and 10 years), and operational (less than a year).

\section{Alternatives}

The review showed that a majority of studies (44) considered 5 or less alternatives (Figure 6A). Nine studies handled over 30 alternatives, and 5 studied a continuous range of possible alternatives in GIS-based approaches. In practice, the types of alternatives considered in the UESP problems were widely diverse, ranging from the evaluation of geographic locations [e.g., siting of hazardous waste landfills (Feo and De Gisi, 2014) or PV recycling plants (Goe et al., 2015)], development scenarios [e.g., comparing environmental-, technology-, and economicdriven energy use scenarios of urban areas (Wang et al., 2011) or policy scenarios (Phdungsilp, 2010)], actions or measures to be implemented by urban actors [e.g., building renovation measures (Medineckiene and Björk, 2011)], or technologies and infrastructure [e.g., community scale RES and technologies, such as solar PV or thermal, wind turbines, geothermal, micro-hydro (Nigim et al., 2004), or residential heating systems (Kontu et al., 2015)]. Alternatives were most often generated or selected by the authors of the studies themselves, followed by alternatives generated by means of optimization methods, expert solicitation, GIS, and literature (Figure 6B). In the context of planning community-scale renewable energy projects, Nigim et al. (2004) 


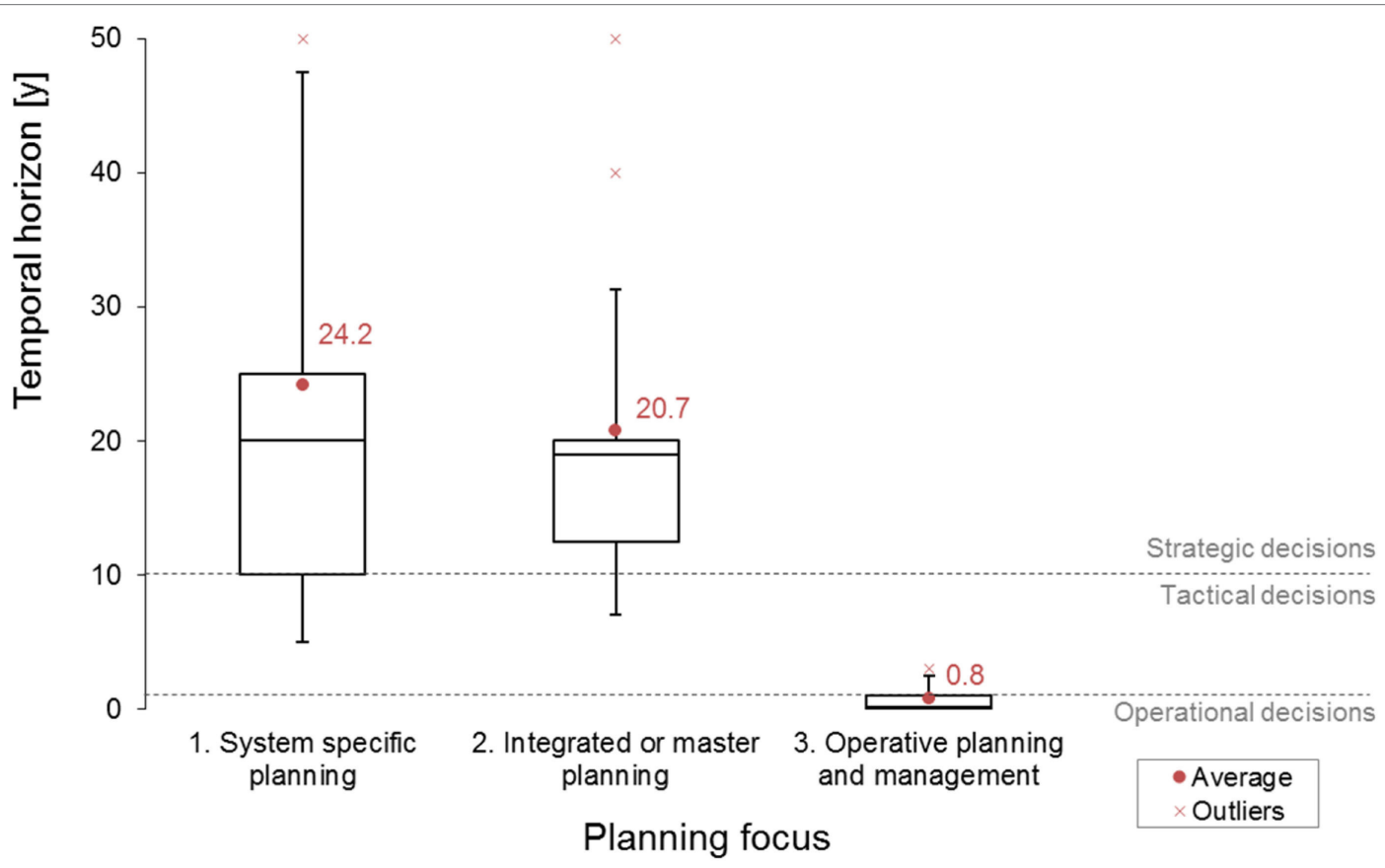

FIGURE 5 | Boxplots of the temporal planning horizons covered by the studies in each planning focus category. The average values for each category are based, respectively, from left to right on 63,18 and 8 studies. Tukey style whiskers extend to points within 1.5 times the interquartile range.

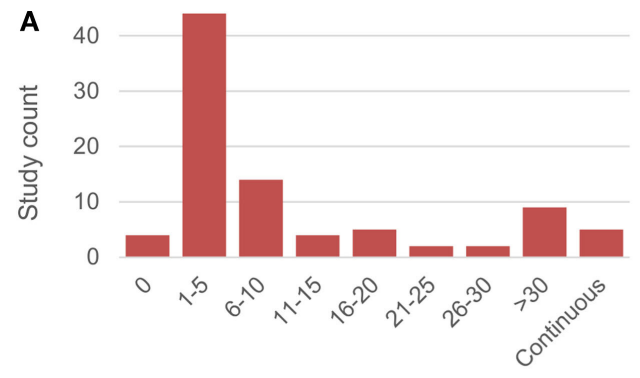

Number of alternatives

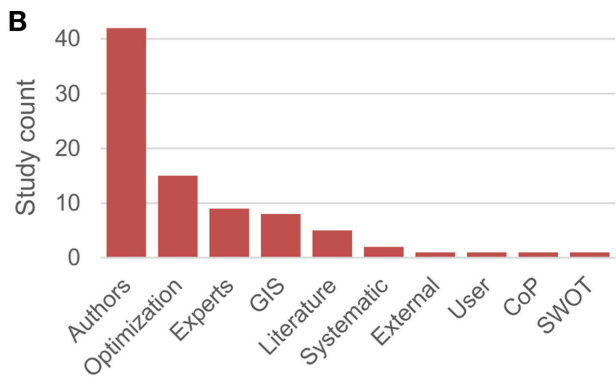

Alternative generation approach

FIGURE 6 | Alternative results from the review. (A) Number of alternatives analyzed by the reviewed studies. The bin "> 30 " includes numbers of alternatives between 30 and 7000, whereas "Continuous" includes studies that relied on Geographic Information System methods. (B) Distribution of alternative generation approaches adopted by the reviewed studies.

write that "an ideal decision environment would include all possible information (...) and every possible alternative." Due to limited time and resources, they note that one must generally deal with limited alternatives. As expressed in other studies, however, this constraint should not prevent the consideration of as many alternatives as possible in the definition of the problem context. When selecting sustainable energy resources, Kaya and Kahraman (2010) and Kontu et al. (2015) underline, for example, the importance of initially considering a broader set of alternative energy resources, including possibly less-popular or less-sustainable options such as fossil or nuclear fuels. Ghafghazi et al. (2010) also consider extended energy sources for a district heating project, explicitly motivating-based on values or problem boundaries-why they keep or reject them in the study.

\section{Criteria}

The typical number of criteria used in the MCDA studies reviewed is between 6 and 10 criteria (Figure 7A). Only two studies used more than 40 criteria. When these were not proposed or developed by the authors themselves, which was found to be the leading approach for criteria elicitation (51), criteria were taken from literature (32), including readily available criteria sets, identified and selected by external experts (17), and occasionally adopting more formalized methods such as Delphi (3) or CoP (1) (Figure 7B). In a study evaluating the appropriateness of technologies for reducing heating costs of impoverished communities (Bauer and Brown, 2014), 49 criteria were ranked according to their prevalence in literature, considering this prevalence as "a proxy for importance." The most cited criteria included, 


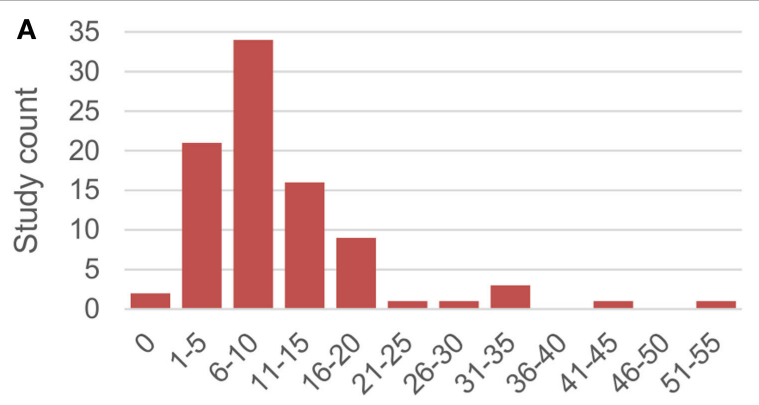

Number of criteria

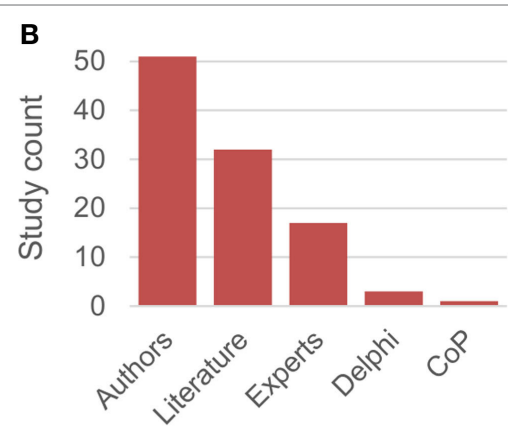

Criteria elicitation approach

FIGURE 7 | Criteria results from the review. (A) Distribution of criteria number used in the reviewed studies. (B) Distribution of criteria elicitation approaches adopted in the reviewed studies.

e.g., community input, affordability, autonomy, or adaptability of the technology. In a second step, the study also ranked these criteria according to local stakeholders, whose ranking differed from the literature-based ranking. Among the top 8 selected criteria were, for example, efficiency of resource use, job creation, simplicity, and autonomy of the technology. This indicates that a literature-based listing of common criteria could be useful as a first step to identify prevalent and possibly important criteria [such a list is for example provided by Wang et al. (2009) for energy supply systems analysis]. However, its practical usability would require further classification and analysis of the criteria by topic and scale. For example, it has been noted that the relevance and perceived importance of criteria such as noise or dust emissions may be higher for small problem boundaries and scales than more global criteria such as $\mathrm{CO}_{2}$ emissions or energy efficiency (Macoun, 2005; Koo and Ariaratnam, 2008). Eventually, some adaptation and extension of the list to meet local specificities is anyway advised (Bauer and Brown, 2014).

\section{Decision Problematic}

The types and number of decision problematics found in the reviewed papers are displayed in Figure 8. Most of the studies aimed at choosing a single best option (i.e., 32 choice problematics), followed by the goal of ranking the alternatives (22). Sixteen studies did not aim to make a decision per se, but rather learn about the decision problem and alternatives involved (description problematic). Bauer and Brown (2014) for example illustrate a description problematic, as the approach does not necessarily aim to choose or rank alternatives, but instead to assess even individual solutions and give them a score that could serve as general advice regarding any solution's quality or "appropriateness." Browne et al. (2010) provide another example of the description problematic, using NAIADE to assess and compare the impacts of energy policy scenarios. They write that the "purpose of NAIADE is not to produce a definitive ranking of alternatives, but to rationalize the problem and provide a framework for communication among stakeholders." Respectively, 13 and 6 studies were of the portfolio and sorting types. Notable portfolio examples consisted for example in combining energy efficiency measures in buildings, choosing from various envelope components and configurations (doors, windows, wall materials), lighting systems and other electrical appliances, and heating systems (Karatas and El-Rayes, 2014; Karmellos et al., 2015), or combining different waste recovery pathways to create municipal recycling programs (Banar et al., 2010). Li et al. (2013) propose a method to sort urban zones according to their potential of underground exploitation, distinguishing high potential zones for short-term exploitation, moderate potential zones to be reserved for long-term projects, and prohibited zones where underground exploitation would conflict with environmental or economic goals.

In Figure 9, the most common MCDA methods used for each decision problematic are shown. Aside from the sorting type, most problematics were addressed with a variety of methods. A few trends can nonetheless be pointed out. MODM methods were predominant in addressing the portfolio problematics. MODM indeed usually works by searching optimal combinations of decision or control variables, which combined form an optimal (or Pareto optimal) solution as regard to the objectives. As noted earlier, this problematic can typically be followed by any other decision problematic. Notable examples were the studies by Pérez-Fortes et al. (2012); Karmellos et al. (2015); Zheng et al. (2015) who followed up with choice or the studies by Karatas and El-Rayes (2013) and Yokoyama and Ito (1995) with description. MODM also proved popular in describing decision problems, as used in one-third of the description problems. A second third is handled with AHP and WSM methods. Single choices were performed predominantly with AHP, WSM, and TOPSIS, whereas ranking also was carried out in $25 \%$ of the cases by ELECTRE III, PROMETHEE, and VIKOR methods.

Regarding supporting methods, Delphi was found particularly often in description problematics, GIS in choice and sorting problematics, and FST was found in all 4 problematics, except portfolio (corresponding charts can be found in the Supplementary Material).

Several authors expressed particular comments regarding desired decision outcome and corresponding choice of methods. Zhang et al. (2014) for example pointed out that depending on the expected outcome, DMs could choose either ELECTRE I when aiming for a choice problematic or ELECTRE II for a ranking 


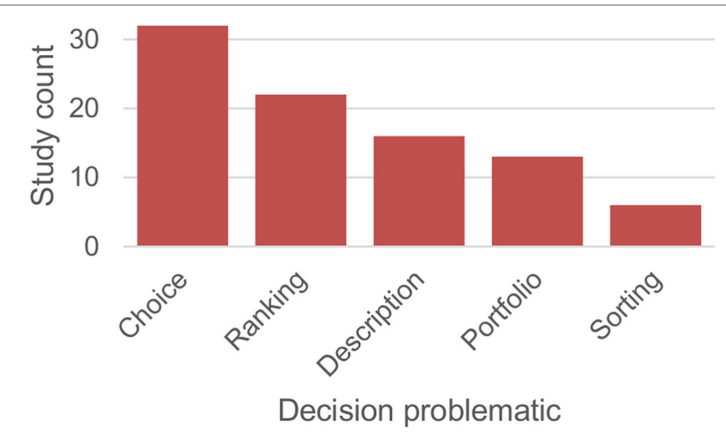

FIGURE 8 | Distribution of problematic types in the reviewed studies.

problematic. Medineckiene and Björk (2011) noted that DMs seeking to learn about worst performing alternatives should avoid resorting to MEW, as this method relies on multiplicative aggregation and tends to rank alternatives at 0 , although these might not be the worst performing over all criteria.

\section{Planning Driver}

According to the characteristics presented above (Figure 4), twothirds of the studies (60) were found to adopt rather value-driven approaches, while the remaining (29 studies) were rather alternative driven. Kontu et al. (2015) illustrates well a value-driven approach, in which values are clearly stated (e.g., sustainable development of energy system, reduced environmental impacts, safeguard economic, and social opportunities) and guide the identification of criteria and alternatives (performed in a collaboration between sustainable energy experts and practitioners). The authors also point out explicitly that alternatives were kept intentionally broad in the beginning, including also fossil fuelbased solutions, only to let the values' associated criteria assess their relevance. The alternatives were of type 2, meaning various heating and electricity components were assessed. Another valuedriven example is provided by the study by González et al. (2013), in which values are clearly expressed and prioritized (sustainable urban development, promotion of positive changes in the urban context, sparing of natural resources, enhancing environmental protection, etc.) and explicitly shaped both the study's objectives, criteria, and alternatives. The alternatives in turn included comprehensive planning measures suited to achieving the values (brownfield rehabilitation, energy efficient housing construction, green space development, etc.).

\section{MCDA Methods}

Similar to previous findings (Zhou et al., 2006; Wang et al., 2009; Mardani et al., 2015; Strantzali and Aravossis, 2016), AHP is found to be the most popular method used for energy related problems (Figure 10). This can in part be explained by its frequent use not only as a MCDA method for criteria aggregation but also as a method to elicit preference weights. Figure $\mathbf{1 0}$ further illustrates the great diversity of methods being used: nearly 30 different MCDA methods have been applied in the 89 studies considered. Besides AHP, only WSM, MODM, TOPSIS, ELECTRE methods, ASPID, VIKOR, PROMETHE methods, and MAUT/MAVT were used more than once. The methods were categorized and counted in Table 2. It was found that value measurements models are the most popular, representing 56\% of all methods used. Second most popular are the MODM methods (15\%), followed by aspiration models (11\%), others (10\%), and outranking methods (8\%).

Similar to the main MCDA methods, Figure 10 also shows the frequency of supporting methods used in the studies, revealing in particular the common use of FST (14), GIS (12), and Delphi (7).

Figure 11 illustrates the predominantly stated arguments for MCDA and supporting methods (the detailed information and references can be found in the Supplementary Material). It can be seen that the choice of a MCDA method was due most frequently to its perceived popularity, stated most often for AHP, WSM, and MODM. The second most frequent argument stated was that of simplicity, which was also expressed as intuitiveness, straightforwardness, transparency, or pragmatism. This argument applied most often to AHP, WSM, TOPSIS, and VIKOR. Equally frequent was the ability to handle qualitative and quantitative information, mainly for AHP and ASPID.

Regarding arguments for choosing supporting methods (Figure 11), the two principle reasons stated were to help in collecting and incorporating human experience and knowledge (applicable by decreasing importance to FST, CoP, Delphi, and OWA) and to cope with incomplete, uncertain, non-measurable, vague, or estimated information (stated for FST and OWA). Other reasons, essentially attributed to Delphi, were to assist in evaluating criteria and weights, as well as eliciting the criteria and alternatives. GIS tools were used mainly for their ability to quickly and simultaneously display multiple data sets, but also for efficient display of information, handling of multiple spatial and temporal scales, and flexibility in combining various tools.

\section{Method Combinations}

In Figure 12, we observe that a majority of studies (54) rely on a single main MCDA method, followed by 20 , which combine 2 main methods and 3 combining 3 main methods. Two studies included up to four main MCDA methods. Ten studies did not include any main MCDA method, which is partly explained by those relying solely on GIS (four studies). When considering also the combination of main and supporting methods together, then a majority of studies appear to contain more than one method.

The most frequent reason for combining methods was the development rationale (26 studies), followed by complementarity (11) and triangulation (9). Secondary rationales were development (8), complementarity (8), and triangulation (1). Although it could be argued that several of the development cases also achieved the purpose of expansion, increasing the breadth of results by application of various specific methods, e.g., those involving Delphi (Haruvy and Shalhevet, 2007; Hsueh and Yan, 2011; Bauer and Brown, 2014; Jain et al., 2014; Vafaeipour et al., 2014), or SWOT (Öztürk, 2015), their sequential flow of information-characteristic of the development type-was deemed most relevant than this latter aspect. As such, no studies involved expansion nor initiation.

The most common development combination was the use of AHP to elicit the weighting of criteria, to be used in other MCDA 

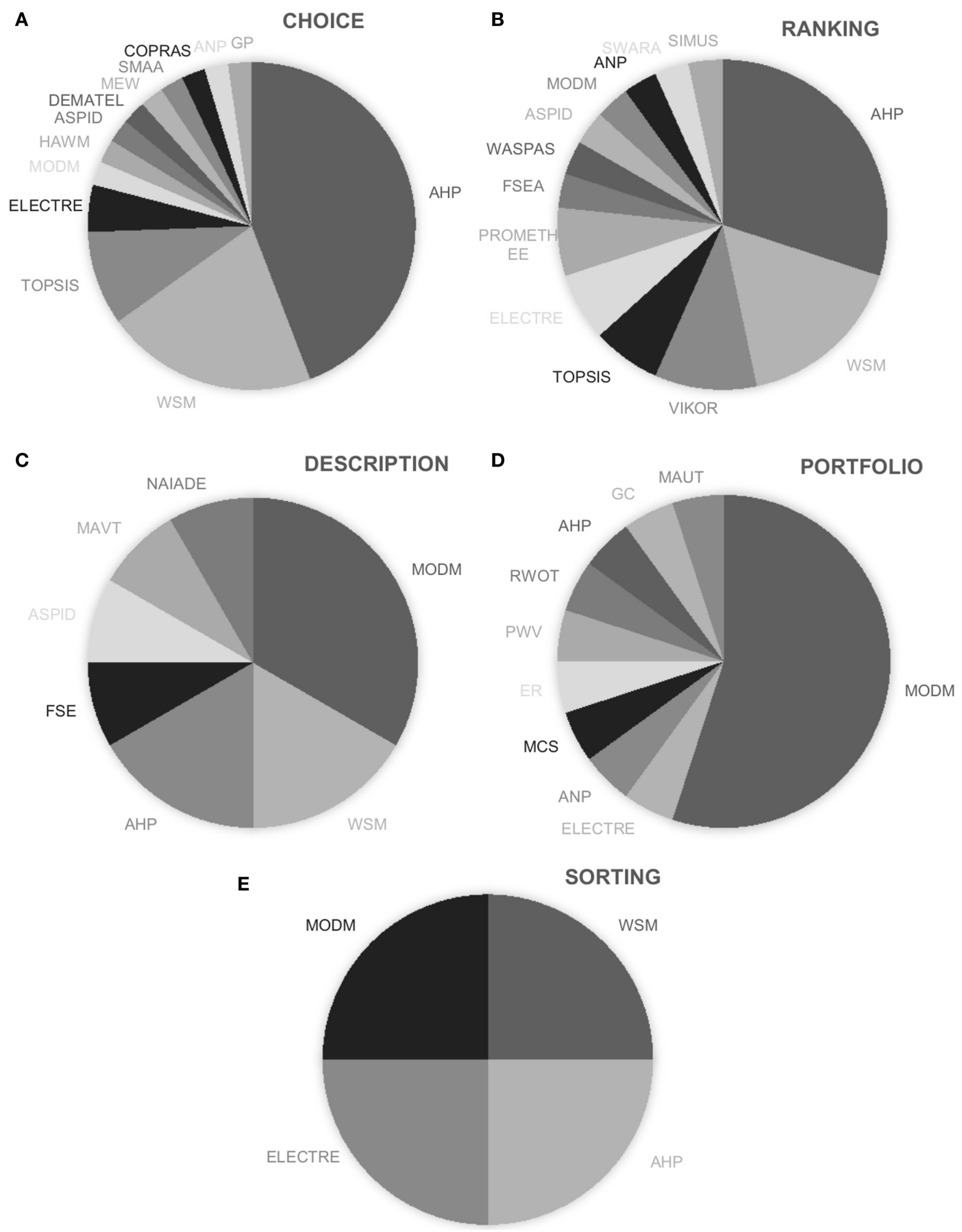

FIGURE 9 | Distribution of multicriteria decision analysis methods used per decision problematic as follows: (A) choice, (B) ranking, (C) description, (D) portfolio, (E) and sorting.

methods, such as TOPSIS (Tzeng et al., 2005; Ekmekçioĝlu et al., 2010; Khoshsolat et al., 2012; Ziemele et al., 2014), WSM (Medineckiene and Björk, 2011; Rochas et al., 2015), and others (Beccali et al., 2002; Kaya and Kahraman, 2010; Duan et al., 2011; Hsu and Lin, 2011; Medineckiene and Björk, 2011; Karatas and El-Rayes, 2013; Fetanat and Khorasaninejad, 2015). The Delphi approach was used in five instances to analyze the decision context while using AHP (Hsueh and Yan, 2011; Jain et al., 2014), WSM (Haruvy and Shalhevet, 2007; Bauer and Brown, 2014), and WASPAS (Vafaeipour et al., 2014) for alternative comparison. Development was also found between MODM/SODM and other MCDA methods in four studies, where WSM (Aydin et al., 2014; Ribau et al., 2015; Fonseca et al., 2016), ER (Zheng et al., 2015), and PWV and GC (Ribau et al., 2015) helped select 


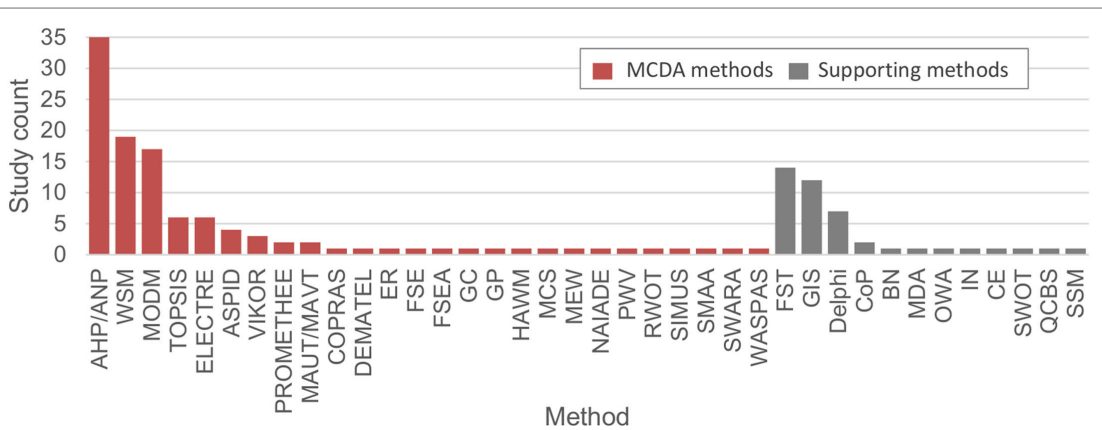

FIGURE 10 | Multicriteria decision analysis (MCDA) and supporting methods used in the reviewed studies. Note: ELECTRE encompasses also ELECTRE III and TRI; PROMETHEE encompasses also PROMETHEE-GAIA.

solutions resulting from optimization calculations. This was also stated as a reason for choosing these methods. One study inverted this pattern, instead making first use of a GIS-based analysis to short-list nine potential locations, which were than incorporated in an MINLP model as decision variables for the optimization calculation (Goe et al., 2015). With nine instances, WSM was the most frequently used as a follow-up method to AHP (Koo and Ariaratnam, 2008; Medineckiene and Björk, 2011; Rochas et al., 2015), optimization (Aydin et al., 2014; Fonseca et al., 2016), Delphi (Haruvy and Shalhevet, 2007; Bauer and Brown, 2014), choice experiment (Dombi et al., 2014), and GIS (Feo and De Gisi, 2014). AHP was also used in a second step in seven studies, benefiting from prior applications of methods such as GIS (Idris and Abd Latif, 2012; Feo and De Gisi, 2014), Delphi as noted above (Hsueh and Yan, 2011; Jain et al., 2014), CoP (Chrysoulakis et al., 2013; González et al., 2013), and FSEA (Wang et al., 2011).

In 12 papers, complementarity was related to the adoption of FST (Ekmekçioĝlu et al., 2010; Kaya and Kahraman, 2010; Duan et al., 2011; Hsu and Lin, 2011; Hsueh and Yan, 2011; Wang et al., 2011; Al-Yahyai et al., 2012; Khoshsolat et al., 2012; Al-Yahyai and Charabi, 2015; Fetanat and Khorasaninejad, 2015; Guo and Zhao, 2015; Colantoni et al., 2016), combining FST with existing methods such as AHP (Ekmekçioĝlu et al., 2010; Kaya and Kahraman, 2010; Duan et al., 2011; Hsu and Lin, 2011; Hsueh and Yan, 2011; Wang et al., 2011; Al-Yahyai et al., 2012; Khoshsolat et al., 2012), ANP, DEMATEL, ELECTRE (Fetanat and Khorasaninejad, 2015), TOPSIS (Ekmekçioĝlu et al., 2010; Khoshsolat et al., 2012; Guo and Zhao, 2015), GIS (Hsu and Lin, 2011; Al-Yahyai et al., 2012; Al-Yahyai and Charabi, 2015; Colantoni et al., 2016), and VIKOR (Kaya and Kahraman, 2010). In three papers, GIS was used, mutually enhancing WSM (Arampatzis et al., 2004), AHP (Al-Yahyai et al., 2012; González et al., 2013), and OWA (Al-Yahyai et al., 2012). MODM was enhanced by MAUT for the aggregation of the objective function (Karatas and El-Rayes, 2013), and by use of an interactive result exploration tool (Nowak et al., 2015). In one case, Bayesian network and WSM were combined (Awad-Núñez et al., 2015).

It is well understood that the choice of MCDA method can influence the final results. Several of the reviewed studies triangulated various methods to compare outcomes either between two common methods, e.g., between ELECTRE III and WSM
(Carriço et al., 2014; Frijns et al., 2015) or ANP (Banar et al., 2010), AHP, and WSM (Feo and De Gisi, 2014), or to assess the results of less common or self-designed methods with more common ones (e.g., between TOPSIS and VIKOR (Tzeng et al., 2005), WSM and QCBS (Vadiati et al., 2012), AHP and a variant of WSM (De Feo et al., 2008), AHP and SIMUS, comparing more specifically differences in subjectivity accounting (Nigim et al., 2004), or WSM with MEW and COPRAS (Medineckiene and Björk, 2011)).

Carriço et al. (2014), Frijns et al. (2015) observed nearly similar results and pointed out that in general, MCDA literature does not discuss which method is most suited for which case nor why results would differ using different methods with same input data. They underline the fact that selecting appropriate methods for different problem types is still an open research question. Feo and De Gisi (2014) compared AHP and WSM variants and were able to obtain similar ranking of the solutions, observing however differences between the relative position of the ranked solutions. Vafaeipour et al. (2014) did not compare the results of WSM and WPM, but relied on a combination of both, arguing it to be more robust. He explicitly recommends in his conclusion to compare results with other well-known MCDA methods.

\section{Synthesis of the Review}

While the previous sections were concerned with the analysis of the reviewed studies, namely examining in detail the various constituents of the multicriteria problem, the present section proposes a synthesis of the present work. A synthesis can be defined as "the combination of components or elements to form a coherent whole" (Oxford Dictionary of English, 2005), and indeed, we hereby bring together the elements of information collected in the review, whose relationships are made coherent by use of parallel coordinates (Figure 13). Parallel coordinates are a convenient and powerful way to handle multivariate data and provide interactive decision support (Packham et al., 2005; Heinrich and Weiskopf, 2013; Johansson and Forsell, 2016). Their use can help identify which methods have been applied in various contexts, providing a guide to select a suitable method. Parallel coordinates consist of vertical axes representing the criteria and of polylines flowing across each axis. Six main criteria have been selected here to represent the characteristics of the 
TABLE 2 | Classifications of multicriteria decision analysis MCDA and supporting methods and share of each class in the 89 studies reviewed.

Type

Group 1. Value measurement models

AHO (Beccali et al., 2002; Yedla and Shrestha, 2003; Nigim et al., 2004, 2009; Tzeng et al.,

2005; Dytczak and Ginda, 2006; De Feo et al.

2008; Koo and Ariaratnam, 2008; Ekmekçioĝlu

et al., 2010; Kaya and Kahraman, 2010;

Massara and Udaeta, 2010; Duan et al., 2011;

Hsu and Lin, 2011; Hsueh and Yan, 2011;

Medineckiene and Björk, 2011; Reza et al.,

2011; Wang et al., 2011; Al-Yahyai et al., 2012;

Idris and Abd Latif, 2012; Khoshsolat et al.,

2012; Chrysoulakis et al., 2013; Daim et al.,

2013; González et al., 2013; Karatas and

El-Rayes, 2013; Madadian et al., 2013; Feo

and De Gisi, 2014; Jain et al., 2014; Ziemele

et al., 2014; Meney and Pantelic, 2015;

Rochas et al., 2015)

WSM (Beccali et al., 2002; Arampatzis

et al., 2004; Haruvy and Shalhevet, 2007;

De Feo et al., 2008; Koo and Ariaratnam,

2008; Jovanović et al., 2009; Afify, 2010;

Medineckiene and Björk, 2011; Vadiati et al.,

2012; Aydin et al., 2014; Bauer and Brown,

2014; Carriço et al., 2014; Dombi et al., 2014;

Feo and De Gisi, 2014; Awad-Núñez et al.,

2015; Frijns et al., 2015; Rochas et al., 2015;

Fonseca et al., 2016)

ASPID (Lipošćak et al., 2006; Jovanovic

et al., 2010, 2011; Vučićević et al., 2014)

SIMUS (Nigim et al., 2004)

ELECTRE (Fetanat

and Khorasaninejad

2015)

Technique for Order

ence by Similarity to

Solutions (Tzeng et a

005; Ekmekçioĝlu et a

2012; Ziemele et al., 2014;

Guo and Zhao, 2015)

\section{ELECTRE III}

Karagiannidis and

Perkoulidis, 2009;

Banar et al., 2010;

Carriço et al., 2014;

Frijns et al., 2015)

Supporting methods

2. Goal, aspiration, and $\quad$ 3. Outranking models 4. Multiobjective $\quad$ 5. Other (fuzzy sets, other

ecision-making

MIN(L)P, EA (Videla

et al., 1990; Yokoyam

agregation methods)

WASPAS (Vafaeipour et al., Geographic information system (Arampatzis and Ito, 1995; Ayoub

et al., 2009; Ma, 2012;

Pérez-Fortes et al.,

2012; Wu et al., 2012;

Al-Ani and Habibi,

2013; Karatas and

El-Rayes, 2013, 2014;

Rager et al., 2013;

Aydin et al., 2014; Ma

et al., 2014; Goe et al.,

2015; Karmellos et al.,

2015; Nowak et al.

2015; Ribau et al.,

2015; Zheng et al.,

2015; Fonseca et al.

\author{
Kar (Tzeng et al., 2005:- PROMETHEE I//GAIA \\ Ghafghazi et al., \\ 2010; Zhang et al., \\ 2014)
}

SWARA Nafaeipour

et al., 2014)

Fuzzy set theory (Ekmekçioĝlu et al., 2010;

Kaya and Kahraman, 2010; Duan et al.

2011; Hsu and Lin, 2011; Hsueh and Yan,

2011; Wang et al., 2011; Al-Yahyai et al.,

2012; Khoshsolat et al., 2012; Al-Yahyai

and Charabi, 2015; Fetanat and

Khorasaninejad, 2015; Guo and Zhao,

2015; Colantoni et al., 2016)

ANP (Bottero and Mondini, 2008; Banar et al.

GP (Nixon et al., 2014)

ELECTRE TRI

(Coelho et al., 2010)

COPRAS (Medineckiene

and Björk, 2011)

FSE (Duan et al., 2011)
Delphi (Tzeng et al, 2005: Haruvy and

Shalhevet, 2007; Hsueh and Yan, 2011;

Bauer and Brown, 2014; Jain et al., 2014; Vafaeipour et al., 2014; Awad-Núñez et al., 2015)

CoP (Chrysoulakis et al., 2013; González et al., 2013) 
MCDA process steps (Figure 1), while the associated MCDA and supporting methods used are presented in the last four axes. Therefore, the correspondence of methods with problem scope, number of alternatives, and criteria is established, allowing endusers to find methods most relevant to their situation. The axes values of temporal scale, number of alternatives, and number of criteria have been clustered for better readability, e.g., temporal scales are represented by the three temporal horizons discussed in Section "Problem Scope." The charts below provide an illustration of the interactive framework. By color coding the various MCDA categories, it becomes clear which methods were predominant for different cases. The following questions can be visually answered, such as:

- Which methods were most adopted for handling many criteria or alternatives?

- Which methods depended the least on supporting methods?

- Which methods were used for which scales and planning focuses?

- Which methods supported which decision problematics?

- Which methods were combined?

Highlighting some of the insights observed in Figure 13, we note that value measurement methods were very eclectic, as altogether they were adopted for nearly scales and decision outcomes (Figure 13B). Goal, aspiration, and reference level methods were essentially used for the urban and neighborhood scales, whereas they were never used for integrated planning or description and sorting problematics (Figure 13C). These methods handled limited number of criteria, never exceeding 20. The outranking group was also fairly eclectic in terms of supporting all decision problematics and rarely required or relied on supporting methods (Figure 13D). They were combined with methods from other groups, including ANP, DEMATEL, and WSM. MODM methods handled multiple scales and planning focuses, while tackling many alternatives, but not more than 20 criteria (Figure 13E). The newer MCDA methods labeled "others" are also fairly broad on all criteria, avoiding however operative planning focus and temporal horizons (Figure 13F). Finally, the studies that did not involve any main MCDA method were also the ones handling the largest amount of alternatives and criteria, in particular because of the use of GIS approaches (Figure 13G).

Figure $\mathbf{1 3 H}$ presents a concrete example illustrating how the parallel coordinates can be used to filter the solutions to match a user's problem context. In the example, the context is defined by "brushing" the axes in the areas of interest, namely to support a planning problem at the urban to district scale, to tackle the system holistically, and to provide either a description of the issues at stake, or to provide support in choosing from a large quantity of alternatives. The chart reveals two methods which that similar conditions: WSM and MODM.

\section{DISCUSSION}

The review revealed several trends and insights on the ongoing applications of MCDA in UESP. The first and most notable 
A

Popular, widely used

Intuitive, simple, straightforward, pragmatic, transparent

MODM

ELECTRE (III, TRI)

Handles quantitative and qualitative information

ASPID

WSM

ANP

Consistency in assigning criteria weights

SWARA

Holistic analysis with many criteria

Copes with vagueness, imprecision, uncertainty, indetermination, inexactness, incompleteness, incomparability

NAIADE

Rational framework for structuring the decision problem

SMAA

ASPAS

- Consistency, reliability, accuracy, robustness

Identifies Pareto-optimal alternatives

- Incorporates requirements and knowledge of stakeholder(s)

- Post analysis of Pareto-optimal fronts

- Handles interdependencies between elements

- Little dependency on subjectivity

TOPSIS

VIKOR
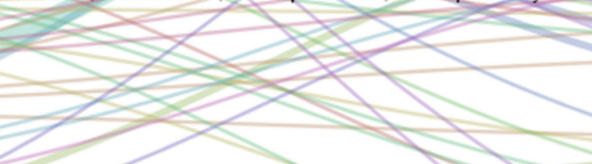

EMATEL $=$

FSEA $=$

$\mathrm{GC}=$

MAUT =

MCS

PWV =

SIMUS -

PRAS -

B

PROMETHEE -

Collect and incorporate human experience and knowledge

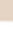

FST

Copes with incomplete, non-measurable, vague, estimated and uncertain information

Evaluate, weigh or rank criteria/altematives

Define and structure criteria/alternatives

Facilitates interaction and consensus among experts

Delphi

Objectivity, accuracy and quantifiability

Simultaneously and quickly analyze multiple data-sets

Efficient and comprehensive visualization of information

Popular

Can be combined with extemal tools

Evaluate spatial/temporal variability

Handles multiple scales

- Initial screening to eliminate alternatives

FIGURE 11 | Stated arguments for selecting the respective (A) multicriteria decision analysis methods and (B) supporting methods. Note: HAWM, MAVT, MEW, RWOT, and QCBS are not represented, as no explicit arguments were provided in the studies. 


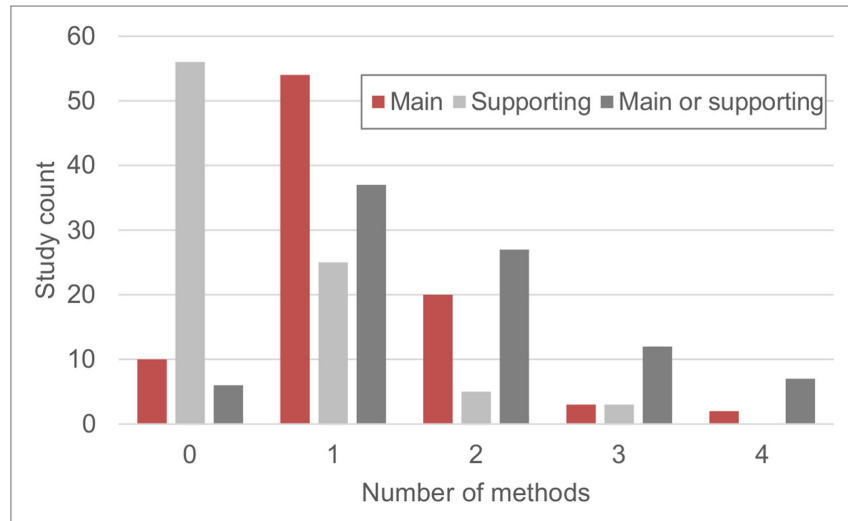

FIGURE 12 | Number of methods used per study.

trend is the increasing use and popularity of these methods in urban energy planning contexts, which can be interpreted in at least two ways. First, this demand for decision analysis and support may reflect the increasing complexity and intractability of issues related to urban energy planning (Cajot et al., 2017), alongside the expectation of accountability and transparency in public authorities' decision-making (Keeney, 1982). MCDA appears in these regards as an appropriate response to support the DMs involved and make their decisions more clear and justifiable. Another interpretation is the growing literature on MCDA, which reinforces its visibility, recognition, validity, and trustworthiness, thus facilitating its dissemination. As Strantzali and Aravossis (2016) also point out that DMs (DM) now tend to resort to a wider variety of methods than before, also building their own methods, when appropriate, to better face their specific issues. If the more traditional methods like AHP, WSM, MODM, and TOPSIS are still the most popular, a broad range of less common methods are tested and applied in attempts to facilitate decisions of urban actors. This was clearly demonstrated in the present selection of studies, as illustrated by the broad range of methods adopted, around $30 \mathrm{MCDA}$ methods found in 89 studies.

The second key finding was the main rationale observed for choosing a method. In nearly 30 papers, one of the main arguments for choosing a method was its popularity. This seems to indicate that DMs are more likely to trust a method that has been intensively studied and applied by peers. In this regard, review papers such as the present help identify these common and popular methods.

Parallel coordinates have been presented here to synthesize the collected review information, providing a means to support analysts and DMs in selecting appropriate methods. It could be argued that the appropriateness of a method does not merely depend on the number of previous applications, which is why the present study strived to provide a deeper context for these applications, underlining not only the most popular methods but also the situations in which they have been applied. Even so, the selection of a method may have been the result of arbitrariness or simply misguided. However, our hypothesis is that previous applications of a method reflect at least some deliberate and motivated reason for doing so, which could in turn be of use for future users in similar contexts. This raises a first point of future work, as this approach grows in relevance by including more studies in the synthesis. As revealed in the review, the topic is currently trending, and it is expected that many more applications of MCDA in UESP will be found in the coming years. It is our hope that the present methodology could serve as a basis for an extension in the near future, investigating evolutions, new trends, and building on the existing base of knowledge.

In addition, if the present results explored in the parallel coordinates may guide end-users in selecting methods, they serve a complementary purpose for decision scientists and researchers, revealing possible research gaps. Therefore, future research may explore the lacks made visible by the parallel coordinates. It was out of the scope of this article to question why, for example, goal and aspiration level methods tended to include only limited criteria compared to other MCDA categories, or avoided the more integrated planning or operative planning problems. Similarly, it was not explored why outranking methods compared fewer alternatives than the other categories. The visual support and comprehensiveness offered by parallel coordinates facilitates this identification of trends, lacks, and subsequent questions, which could be explored in future work.

The review has also looked at the reasons for combining various methods. It became clear that MCDA can benefit from multimethod approaches, as more than half of the studies relied on a combination of MCDA and supporting methods, and about a third used a combination of two or more MCDA methods. The leading rationale for combining methods was development, with AHP frequently used for weight elicitation, Delphi for analyzing the decision context, and between various optimization and other MCDA methods. Ten studies explicitly aimed to triangulate and compare different MCDA methods, and two trends were observed here: first, triangulation that aimed at comparing common methods, and second, triangulation between a common method and a less known one. This tends to show that users of MCDA are fairly cautious in their adoption of existing or new methods and do realize the advantages of comparing several methods for an enhanced understanding of the problems.

The review focused on the context of UESP, thereby providing useful information about an emerging topic. The studies revealed that urban energy questions indeed span over decades, increasing the challenges and uncertainties in the decision process. Most planning questions concerned temporal horizons of over 20 years, meaning investments and effects will last at least that long and are worthy of analytical decision support. It was also found that although the leading topics of study were heating, cooling, and power, a wider balance with topics of mobility, water, environment, and waste also exists. However, as was already pointed out by Løken (2007), the integration of carriers and technologies is still fairly rare, as a majority of studies remain system specific. Few studies dealt with operative planning, and here as well, future work to better link the specific planning and design studies with effects at the operative stage would prove useful. Regarding the lack of studies on the urban and local scale also noted in the introduction, the number 


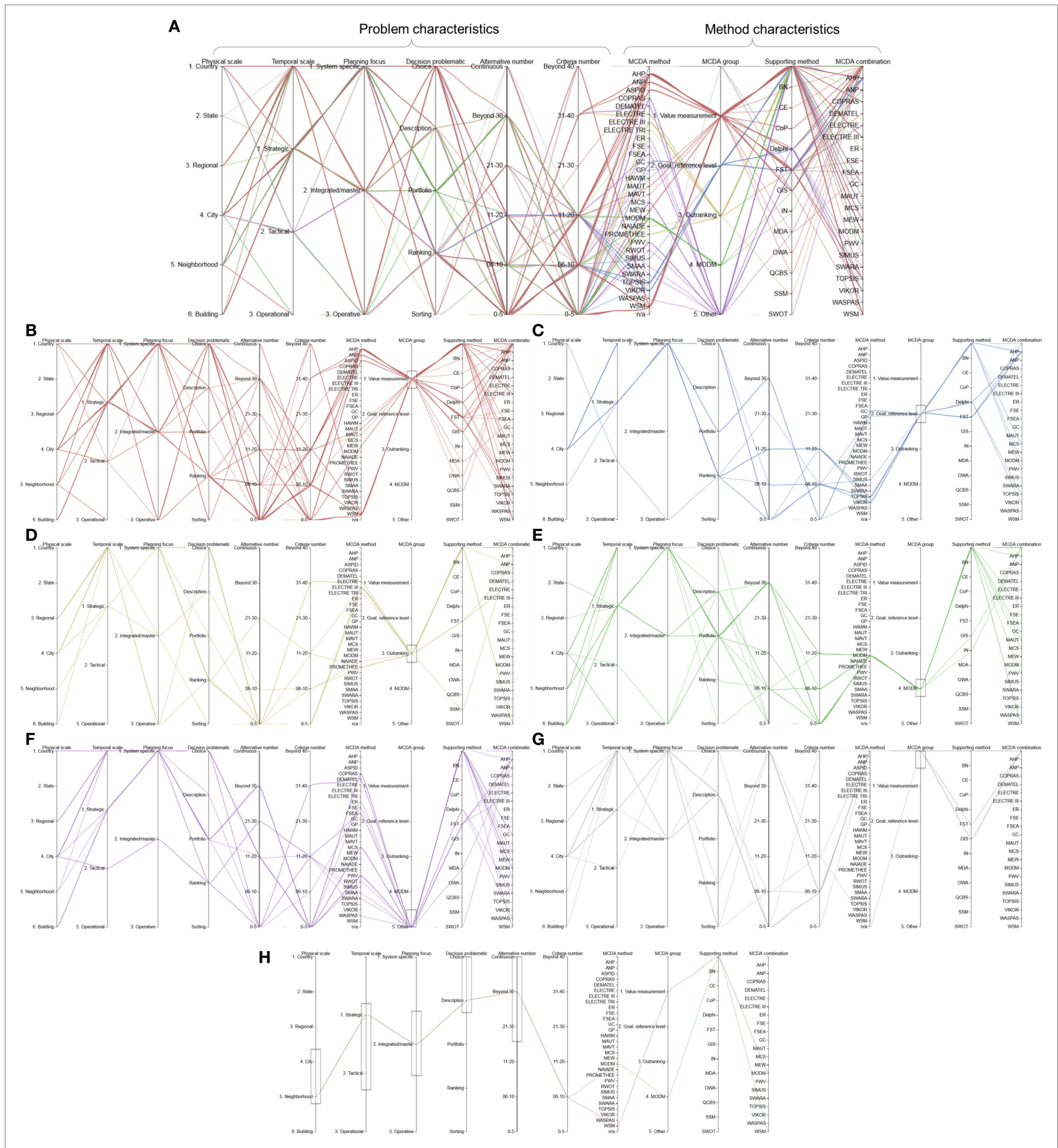

FIGURE 13 | Synthesis of data collected from the reviewed papers, depicted in parallel coordinates. See Supplementary material to access the interactive charts. (A) All methods displayed with their corresponding characteristics. (B-G) Filtering of the methods by multicriteria decision analysis group. (H) Identification of the methods matching a user-defined planning problem, by brushing the corresponding axes.

of studies found in the context of this review seems to indicate that the awareness of the importance of this topic has grown in the past decade and will certainly continue expanding.
Another noticeable trend was the combination of MCDA with various supporting methods like Delphi, CoP, or SWOT, which help structure the problem, identify alternatives and 
criteria, and prioritize them. In turn, this helped DMs better focus on values. Even without the use of supporting methods to elicit values, a majority of studies were considered driven by values, rather than alternatives. This is rather encouraging, as it reflects a healthier approach to decision analysis and problem solving, by promoting the analysis of many alternatives, leading to better decisions. Nevertheless, still one-third of the studies focused on alternatives, possibly failing to identify better, more adapted solutions.

\section{CONCLUSION}

The urban context and urban planning has a crucial role to play in shaping tomorrow's urban energy systems. The complexity of the tasks requires, however, appropriate decision analysis and support, and it appears that MCDA has a bright and necessary future in UESP. Contributing to the knowledge in these areas, this article first provided a definition of the concept of UESP and presented a systematic review and analysis of MCDA applications in this context. It investigated issues that were not tackled by previous reviews in the field, including criteria and alternative elicitation, reasons for choosing and combining methods, decision problematics, and values. Synthesizing the collected information, an interactive framework was proposed to help future users identify appropriate MCDA methods relevant to their problems.

The review allowed to respond to previous lacks identified in energy related MCDA applications, highlighted in the Section "Introduction." Indeed, the review revealed a growing body of studies focusing on the urban and neighborhood scales, previously only sparsely addressed. It also indicated that the MCDA approaches combined multiple methods more often than not, which has been advocated by Løken (2007) and (Hobbs and Horn, 1997). Finally, 18 studies were found, which tackled the energy system in an integrated way, considering various energy carriers or sectors. Although this is still a minority compared to the 61 system specific studies, there is hope that more integrated approaches will take place in the future, with the rising awareness and competences in interdisciplinary work, and increasing computational power capable of modeling large, integrated systems with greater detail and accuracy.

At the same time, new issues have emerged, and several questions have not yet been explored.

- The proliferation of MCDA methods and applications seems to indicate a flourishing research area, but at the same time decreases the accessibility to-and understanding of - the methods by novices. Future reviews should focus more specifically on organizing the new methods being developed, clarifying the practical implications of using one method rather than another. Such transparency and structure is required for the field of MCDA to successfully reach out and support those who could benefit from them.

- The role and background of DMs, their number, the inclusion of citizens, and the effect these aspects may have on the choice of MCDA method is a facet, which was not investigated in the scope of this review. Given the tendency of urban planning to involve wider groups of stakeholders [e.g., in collaborative planning approaches (Teriman et al., 2010; Cajot et al., 2017)], this research question could highlight which methods are most suitable for decisions including large groups. Certain studies reviewed here have been more explicit in describing these stakeholder interactions and could be a starting point for analysis (Yedla and Shrestha, 2003; Nigim et al., 2004; Tzeng et al., 2005; Dytczak and Ginda, 2006; Wang et al., 2011; Vafaeipour et al., 2014).

- The multiple uncertainties in the real planning processes (Mirakyan and De Guio, 2013b), as well as the many different approaches to cope with them (Mirakyan and De Guio, 2015) were not treated in this work for time and space limitations. As highlighted in the review, urban planning projects span over an average of 20-25 years, implying planners must be able to incorporate a certain flexibility in their plans, handling uncertainties related to not only the relevance of energy technologies available today, but also those which may become available in the next decades.

- Criteria were only explored here quantitatively and according to their selection process. Following the approach of Wang et al. (2009), a compilation could be done as well in the area of UESP, providing DMs with a qualitative overview of the commonly used criteria, classified by scale and topic. Wang et al. (2009) also discussed how a proliferation of criteria is not necessarily helping take better decisions, listing five principles to follow for their selection (systemic, consistency, independence, measurability, and comparability). Investigating how these rules are respected in practice, in particular whether the criteria represent well the systems studied, and whether they are truly independent, could bring insights to the validity of the results in MCDA literature.

- In addition, the recurrent methods and tools employed not only to elicit but also to evaluate the criteria could be investigated.

These open topics, as well as the approach and review questions presented in this article, could also be extended to a broader sample of studies (exploring, e.g., other databases, languages, master and doctoral dissertations, books, unpublished studies, future studies), in the topic of urban energy planning and beyond.

\section{NOMENCLATURE}

\begin{tabular}{ll}
\hline AHP & Analytic Hierarchy Process \\
ANP & Analytic Network Process \\
ASPID & Analysis and Synthesis of Parameters under \\
& Information Deficiency \\
BN & Bayesian Network \\
CBA & Cost-Benefit Analysis \\
CE & Choice Experiment \\
COP & Communities of Practice \\
COPRAS & COmplex PRoportional ASsessment \\
DEMATEL & DEcision MAking Trial and Evaluation Laboratory \\
DM & Decision Maker \\
ELECTRE & ELimination Et Choix Traduisant la REalité (from \\
& French, ELimination And Choice Transcribing Reality)
\end{tabular}




\begin{tabular}{ll} 
ER & Evidential Reasoning \\
EU & European Union \\
FST & Fuzzy Set Theory \\
FSEA & Fuzzy synthetic extent analysis \\
FSE & Fuzzy Synthetic Evaluation \\
GAIA & Geometrical Analysis for Interactive Aid \\
GC & Global Criterion \\
GHG & Greenhouse Gas \\
GIS & Geographic Information System \\
GP & Goal Programming \\
HAWM & Hierarchical Additive Weighting Method \\
IEA & International Energy Agency \\
IPCC & Intergovernmental Panel on Climate Change \\
MAUT & Multi-Attribute Utility Theory \\
MAVT & Multiple-Attribute Value Theory \\
MCDA & Multi-Criteria Decision Analysis \\
MCDM & Multiple Criteria Decision Making \\
MCS & Multiple Criteria Score \\
MEW & Multiplicative Exponential Weighting \\
MI(N)LP & Mixed Integer (Non) Linear Programming \\
MODM & Multi-Objective Decision Making \\
NAIADE & Novel Approach to Imprecise Assessment and \\
& Decision Environments \\
NoP & Network of Problems \\
OWA & Ordered Weighted Averaging \\
PWV & Pseudo-Weight Vector \\
PROMETHEE & Preference Ranking Organization Method for. \\
& Enrichment Evaluations \\
QCBS & Quality and Cost Based Selection \\
RES & Renewable energy sources \\
SIMUS & Sequential Interactive Modeling for Urban Systems \\
SMAA & Stochastic Multiobjective Acceptability Analysis \\
SODM & Single-Objective Decision Making \\
SSM & Soft Systems Methodology \\
SWARA & Step-wise Weight Assessment Ratio Analysis \\
SWOT & Strengths, weaknesses, opportunities and threats \\
TOPSIS & Technique for Order Preference by Similarity to Ideal \\
UES & Solutions \\
UESP & Urban Energy System \\
UN & Unban Energy System Planning \\
\hline &
\end{tabular}

\section{REFERENCES}

Aalborg Charter. (1994). Charter of European Sustainable Cities and Towns Towards Sustainability. Aalborg: European Conference on Sustainable Cities \& Towns.

Afify, A. (2010). Prioritizing desalination strategies using multi-criteria decision analysis. Desalination 250, 928-935. doi:10.1016/j.desal.2009.03.005

Al-Ani, D., and Habibi, S. (2013). Optimal operation of water pumping stations. WIT Trans. Ecol. Environ. 178, 185-198. doi:10.2495/WS130161

Albers, G. (1986). Changes in German town planning: a review of the last sixty years. Town Plan. Rev. 57, 17-34. doi:10.3828/tpr.57.1.c7gv551q62027012

Al-Shemmeri, T., Al-Kloub, B., and Pearman, A. (1997). Model choice in multicriteria decision aid. Eur. J. Oper. Res. 97, 550-560. doi:10.1016/S03772217(96)00277-9

Al-Yahyai, S., and Charabi, Y. (2015). Assessment of large-scale wind energy potential in the emerging city of Duqm (Oman). Renew. Sustain. Energy Rev. 47, 438-447. doi:10.1016/j.rser.2015.03.024

Al-Yahyai, S., Charabi, Y., Gastli, A., and Al-Badi, A. (2012). Wind farm land suitability indexing using multi-criteria analysis. Renew. Energy 44, 80-87. doi:10.1016/j.renene.2012.01.004

Arampatzis, G., Kiranoudis, C. T., Scaloubacas, P., and Assimacopoulos, D. (2004). A GIS-based decision support system for planning urban transportation policies. Eur. J. Oper. Res. 152, 465-475. doi:10.1016/S0377-2217(03)00037-7

Awad-Núñez, S., González-Cancelas, N., Soler-Flores, F., and Camarero-Orive, A. (2015). How should the sustainability of the location of dry ports be measured? A proposed methodology using Bayesian networks and multi-criteria decision analysis. Transport 30, 312-319. doi:10.3846/16484142.2015.1081618

$\begin{array}{ll}\text { UNCED } & \text { United Nations Conference on Environment and } \\ & \text { Development } \\ \text { VIKOR } & \text { VIseKriterijumska Optimizacija I kompromisno } \\ & \text { Resenje (from Serbian, MUltiCriteria Optimization and } \\ & \text { compromise Solution) } \\ \text { WASPAS } & \text { Weighted Aggregated Sum Product ASsessment } \\ \text { WPM } & \text { Weighted Product Model } \\ \text { WSM } & \text { Weighted Sum Model }\end{array}$

\section{AUTHOR CONTRIBUTIONS}

All authors contributed substantially to the conception of the work and to its intellectual content, and approved the final version.

\section{ACKNOWLEDGMENTS}

The authors would like to thank the developers from syntagmatic. github.io/parallel-coordinates and raw.densitydesign.org, who enabled the generation of the parallel coordinates charts and alluvial diagrams in this paper, respectively.

\section{FUNDING}

The authors gratefully acknowledge the European Commission for providing financial support during the conduct of research under the FP7-PEOPLE-2013 Marie Curie Initial Training Network "CI-NERGY” project with Grant Agreement Number 606851.

\section{SUPPLEMENTARY MATERIAL}

The Supplementary Material for this article can be found online at http://journal.frontiersin.org/article/10.3389/fenrg.2017.00010/ full\#supplementary-material.

Aydin, N. Y., Mays, L., and Schmitt, T. (2014). Technical and environmental sustainability assessment of water distribution systems. Water Resour. Manag. 28, 4699-4713. doi:10.1007/s11269-014-0768-y

Ayoub, N., Elmoshi, E., Seki, H., and Naka, Y. (2009). Evolutionary algorithms approach for integrated bioenergy supply chains optimization. Energy Convers. Manag. 50, 2944-2955. doi:10.1016/j.enconman.2009.07.010

Balint, P. J., Stewart, R. E., Desai, A., and Walters, L. C. (2011). Wicked Environmental Problems: Managing Uncertainty and Conflict. Washington, DC: Island Press.

Banar, M., Özkan, A., and Kulaç, A. (2010). Choosing a recycling system using ANP and ELECTRE III techniques. Turk. J. Eng. Environ. Sci. 34, 145-154. doi:10.3906/muh-0906-47

Bauer, A. M., and Brown, A. (2014). Quantitative assessment of appropriate technology. Proc. Eng. 78, 345-358. doi:10.1016/j.proeng.2014.07.076

Beccali, G., Cellura, M., and Mistretta, M. (2002). "A user-friendly software for sustainable management of urban areas," in Ninth International Conference on the Modelling, Monitoring and Management of Environmental Problems, ENVIROSOFT 2002, Vol. 7. Bergen, Norway: WIT Press.

Belton, V., and Stewart, T. J. (2002). Multiple Criteria Decision Analysis. Boston, MA: Springer.

Bottero, M., and Mondini, G. (2008). An appraisal of analytic network process and its role in sustainability assessment in Northern Italy. Manag. Environ. Qual. 19, 642-660. doi:10.1108/14777830810904885

Browne, D., O’Regan, B., and Moles, R. (2010). Use of multi-criteria decision analysis to explore alternative domestic energy and electricity policy scenarios in an Irish city-region. Energy 35, 518-528. doi:10.1016/j.energy.2009.10.020

C40, Arup. (2014). Climate Action in Megacities 2.0. London: C40. 
C40, Arup, UCL. (2015). Powering Climate Action: Cities as Global Changemakers. London: $\mathrm{C} 40$.

Cajot, S., Peter, M., Bahu, J.-M., Guignet, F., Koch, A., and Maréchal, F. (2017). Obstacles in energy planning at the urban scale. Sustain. Cities Soc. doi:10.1016/j. scs.2017.02.003

Cajot, S., Peter, M., Bahu, J.-M., Koch, A., and Maréchal, F. (2015). Energy planning in the urban context: challenges and perspectives. Energy Procedia 78 , 3366-3371. doi:10.1016/j.egypro.2015.11.752

Caputo, P., and Pasetti, G. (2015). Overcoming the inertia of building energy retrofit at municipal level: the Italian challenge. Sustain. Cities Soc. 15, 120-134. doi:10.1016/j.scs.2015.01.001

Carriço, N. J. G., Veríssimo Gonçalves, F., Covas, D. I. C., Do Céu Almeida, M., and Alegre, H. (2014). Multi-criteria analysis for the selection of the best energy efficient option in urban water systems. Proc. Eng. 70, 292-301. doi:10.1016/j. proeng.2014.02.033

Chapuis, A., Cherix, G., Capezzali, M., Püttgen, H. B., and Finger, M. (2010). A Conceptual Framework for Energy Planning and $\mathrm{CO}_{2}$ Emissions Counting in Urban Areas. Berlin: Conference on Applied Infrastructure Research.

Chen, Y. (2006). Multiple Criteria Decision Analysis: Classification Problems and Solutions. Waterloo, ON: University of Waterloo.

Chrysoulakis, N., Lopes, M., San José, R., Grimmond, C. S. B., Jones, M. B., Magliulo, V., et al. (2013). Sustainable urban metabolism as a link between bio-physical sciences and urban planning: the BRIDGE project. Landsc. Urban Plan. 112, 100-117. doi:10.1016/j.landurbplan.2012.12.005

Coelho, D., Antunes, C. H., and Martins, A. G. (2010). Using SSM for structuring decision support in urban energy planning. Ukio Technol. Ekon. Vystym. 16, 641-653. doi:10.3846/tede.2010.39

Cohon, J. L. (1978). Multiobjective Programming and Planning. Mineola, NY: Courier Corporation.

Colantoni, A., Delfanti, L., Recanatesi, F., Tolli, M., and Lord, R. (2016). Land use planning for utilizing biomass residues in Tuscia Romana (central Italy): preliminary results of a multi criteria analysis to create an agro-energy district. Land use policy 50, 125-133. doi:10.1016/j.landusepol.2015.09.012

Connelly, S., and Richardson, T. (2005). Value-driven SEA: time for an environmental justice perspective? Environ. Impact Assess. Rev. 25, 391-409. doi:10.1016/j. eiar.2004.09.002

Covenant of Mayors. (2016). Covenant of Mayors 2016. Available at: www.covenantofmayors.eu

Crump, B., and Logan, K. (2008). "A framework for mixed stakeholders and mixed methods," in Proc. 7th Eur. Conf. Res. Methodol. Bus. Manag. Stud. ECRM2008 (London, UK: Academic Conferences Limited), 111.

Daim, T. U., Bhatla, A., and Mansour, M. (2013). Site selection for a data centre - a multi-criteria decision-making model. Int. J. Sustain. Eng. 6, 10-22. doi:10.108 0/19397038.2012.719554

De Feo, G., De Gisi, S., and Galasso, M. (2008). Definition of a practical multicriteria procedure for selecting the best coagulant in a chemically assisted primary sedimentation process for the treatment of urban wastewater. Desalination 230, 229-238. doi:10.1016/j.desal.2007.12.003

Dodgson, J. S., Spackman, M., Pearman, A., and Phillips, L. D. (2009). MultiCriteria Analysis: A Manual. London: Department for Communities and Local Government.

Dombi, M., Kuti, I., and Balogh, P. (2014). Sustainability assessment of renewable power and heat generation technologies. Energy Policy 67, 264-271. doi:10.1016/j.enpol.2013.12.032

Duan, Z., Pang, Z., and Wang, X. (2011). Sustainability evaluation of limestone geothermal reservoirs with extended production histories in Beijing and Tianjin, China. Geothermics 40, 125-135. doi:10.1016/j. geothermics.2011.02.001

Dytczak, M., and Ginda, G. (2006). Benefits and costs in selecting fuel for municipality heating systems with the analytic hierarchy process. J. Syst. Sci. Syst. Eng. 15, 165-177. doi:10.1007/s11518-006-5005-7

EC. (2007). Limiting Global Climate Change to 2 Degrees Celsius - The Way Ahead for 2020 and Beyond. Brussels: European Commission.

EC. (2014). A Policy Framework for Climate and Energy in the Period from 2020 to 2030. Brussels: European Commission.

Ekmekçioĝlu, M., Kaya, T., and Kahraman, C. (2010). Fuzzy multicriteria disposal method and site selection for municipal solid waste. Waste Manag. 30, 1729-1736. doi:10.1016/j.wasman.2010.02.031
Feng, C.-M., and Lin, J.-J. (1999). Using a genetic algorithm to generate alternative sketch maps for urban planning. Comput. Environ. Urban Syst. 23, 91-108. doi:10.1016/S0198-9715(99)00004-6

Feo, G. D., and De Gisi, S. (2014). Using MCDA and GIS for hazardous waste landfill siting considering land scarcity for waste disposal. Waste Manag. 34, 2225-2238. doi:10.1016/j.wasman.2014.05.028

Fetanat, A., and Khorasaninejad, E. (2015). A novel hybrid MCDM approach for offshore wind farm site selection: a case study of Iran. Ocean Coast. Manag. 109, 17-28. doi:10.1016/j.ocecoaman.2015.02.005

Fonseca, J. A., Nguyen, T.-A., Schlueter, A., and Marechal, F. (2016). City energy analyst (CEA): integrated framework for analysis and optimization of building energy systems in neighborhoods and city districts. Energy Build. 113, 202-226. doi:10.1016/j.enbuild.2015.11.055

Frijns, J., Marchet, E. C., Carriço, N., Covas, D., Monteiro, A. J., Ramos, H. M., et al. (2015). Management tools for hydro energy interventions in water supply systems. Water Pract. Technol. 10, 214-228. doi:10.2166/wpt.2015.024

Ghafghazi, S., Sowlati, T., Sokhansanj, S., and Melin, S. (2010). A multicriteria approach to evaluate district heating system options. Appl. Energy 87, 1134-1140. doi:10.1016/j.apenergy.2009.06.021

Goe, M., Gaustad, G., and Tomaszewski, B. (2015). System tradeoffs in siting a solar photovoltaic material recovery infrastructure. J. Environ. Manage. 160, 154-166. doi:10.1016/j.jenvman.2015.05.038

González, A., Donnelly, A., Jones, M., Chrysoulakis, N., and Lopes, M. (2013). A decision-support system for sustainable urban metabolism in Europe. Environ. Impact Assess. Rev. 38, 109-119. doi:10.1016/j.eiar.2012.06.007

Gossop, C. (2011). Low carbon cities: an introduction to the special issue. Cities 28, 495-497. doi:10.1016/j.cities.2011.09.003

Greco, S., Ehrgott, M., and Figueira, J. R. (eds) (2016). Multiple Criteria Decision Analysis, Vol. 233. New York, NY: Springer.

Greene, J. C., Caracelli, V. J., and Graham, W. F. (1989). Toward a conceptual framework for mixed-method evaluation designs. Educ. Eval. Policy Anal. 11, 255-274. doi:10.3102/01623737011003255

Grubert, E. A., Stillwell, A. S., and Webber, M. E. (2014). Where does solar-aided seawater desalination make sense? A method for identifying sustainable sites. Desalination 339, 10-17. doi:10.1016/j.desal.2014.02.004

Guitouni, A., and Martel, J.-M. (1998). Tentative guidelines to help choosing an appropriate MCDA method. Eur. J. Oper. Res. 109, 501-521. doi:10.1016/ S0377-2217(98)00073-3

Guo, S., and Zhao, H. (2015). Optimal site selection of electric vehicle charging station by using fuzzy TOPSIS based on sustainability perspective. Appl. Energy 158, 390-402. doi:10.1016/j.apenergy.2015.08.082

Habitat-Iclei, U. (2009). Sustainable Urban Energy Planning: A Handbook for Cities and Towns in Developing Countries. Nairobi: UNON, Publishing Services Section.

Haruvy, N., and Shalhevet, S. (2007). Risk Assessment of the Effect of Wastewater Treatment and Desalination Processes on the Coastal Aquifer in Israel: Using Multi-Criteria Decision Analysis.

Healey, P. (2004). The treatment of space and place in the new strategic spatial planning in Europe. Int. J. Urban Reg. Res. 28, 45-67. doi:10.1111/j. 0309-1317.2004.00502.x

Heinrich, J., and Weiskopf, D. (2013). "State of the art of parallel coordinates," in Eurographics 2013 - State of the Art Reports. Presented at the Eurographics 2013 - STARs, The Eurographics Association, Girona, Spain, 95-116.

Hobbs, B. F., and Horn, G. T. (1997). Building public confidence in energy planning: a multimethod MCDM approach to demand-side planning at BC gas. Energy Policy 25, 357-375. doi:10.1016/S0301-4215(97)00025-6

Hopkins, L. D. (2001). Urban Development: The Logic of Making Plans. Washington, DC: Island Press.

Hsu, T. P., and Lin, Y. T. (2011). A model for planning a bicycle network with multi-criteria suitability evaluation using GIS. WIT Trans. Ecol. Environ. 148, 243-252. doi:10.2495/RAV110231

Hsueh, S.-L., and Yan, M.-R. (2011). Enhancing sustainable community developments: a multi-criteria evaluation model for energy efficient project selection. Energy Proc. 5, 135-144. doi:10.1016/j.egypro.2011.03.025

Huang, J. P., Poh, K. L., and Ang, B. W. (1995). Decision analysis in energy and environmental modeling. Energy 20, 843-855. doi:10.1016/0360-5442(95)00036-G

Hwang, C.-L., and Masud, A. S. (eds) (1979). Multiple Objective Decision Making: Methods and Applications; A State-of-the-Art Survey. 
Idris, R., and Abd Latif, Z. (2012). "GIS multi-criteria for power plant site selection," in Proceedings - 2012 IEEE Control and System Graduate Research Colloquium, ICSGRC 2012, 203-206.

IEA. (2008). World Energy Outlook. STEDI MEDIA. Paris: IEA Publications.

Immendoerfer, A., Winkelmann, M., and Stelzer, V. (2014). Energy Solutions for Smart Cities and Communities - Recommendations for Policy Makers. Stuttgart: European Union.

IPCC. (2014). "Summary for policymakers," in Clim. Change 2014 Mitig. Clim. Change Contrib. Work. Group III Fifth Assess. Rep. Intergov. Panel Clim. Change, eds O. Edenhofer, R. Pichs-Madruga, Y. Sokona, E. Farahani, S. Kadner, K. Seyboth, and A. Adler (Cambridge; New York, NY: Cambridge University Press), 21-26.

Jain, S., Aggarwal, P., Kumar, P., Singhal, S., and Sharma, P. (2014). Identifying public preferences using multi-criteria decision making for assessing the shift of urban commuters from private to public transport: a case study of Delhi. Transp. Res. Part F Traffic Psychol. Behav. 24, 60-70. doi:10.1016/j.trf.2014.03.007

Johansson, J., and Forsell, C. (2016). Evaluation of parallel coordinates: overview, categorization and guidelines for future research. IEEE Trans. Vis. Comput. Graph 22, 579-588. doi:10.1109/TVCG.2015.2466992

Jovanovic, M., Afgan, N., and Bakic, V. (2010). An analytical method for the measurement of energy system sustainability in urban areas. Energy 35, 3909-3920. doi:10.1016/j.energy.2010.06.010

Jovanović, M., Afgan, N., Radovanović, P., and Stevanović, V. (2009). Sustainable development of the Belgrade energy system. Energy 34, 532-539. doi:10.1016/j. energy.2008.01.013

Jovanovic, M., Turanjanin, V., Bakic, V., Pezo, M., and Vucicevic, B. (2011). Sustainability estimation of energy system options that use gas and renewable resources for domestic hot water production. Energy 36, 2169-2175. doi:10.1016/j.energy.2010.08.042

Karagiannidis, A., and Perkoulidis, G. (2009). A multi-criteria ranking of different technologies for the anaerobic digestion for energy recovery of the organic fraction of municipal solid wastes. Bioresour. Technol. 100, 2355-2360. doi:10.1016/j.biortech.2008.11.033

Karatas, A., and El-Rayes, K. (2013). Optimizing tradeoffs among housing sustainability objectives. Autom. Constr. 53, 83-94. doi:10.1016/j.autcon.2015.02.010

Karatas, A., and El-Rayes, K. (2014). Optimal trade-offs between social quality of life and life-cycle cost in housing units. J. Constr. Eng. Manag. 140. doi:10.1061/ (ASCE)CO.1943-7862.0000895

Karmellos, M., Kiprakis, A., and Mavrotas, G. (2015). A multi-objective approach for optimal prioritization of energy efficiency measures in buildings: model, software and case studies. Appl. Energy 139, 131-150. doi:10.1016/j. apenergy.2014.11.023

Kaya, T., and Kahraman, C. (2010). Multicriteria renewable energy planning using an integrated fuzzy VIKOR \& AHP methodology: the case of Istanbul. Energy 35, 2517-2527. doi:10.1016/j.energy.2010.02.051

Keeney, R. L. (1982). Decision analysis: an overview. Oper. Res. 30, 803-838. doi:10.1287/opre.30.5.803

Keeney, R. L. (1992). Value-Focused Thinking: A Path to Creative Decision Making. Cambridge: Harvard University Press.

Keeney, R. L., Renn, O., and von Winterfeldt, D. (1987). Structuring West Germany's energyobjectives.Energy Policy 15,352-362. doi:10.1016/0301-4215(87)90025-5

Keirstead, J., Jennings, M., and Sivakumar, A. (2012). A review of urban energy system models: approaches, challenges and opportunities. Renew. Sustain. Energy Rev. 16, 3847-3866. doi:10.1016/j.rser.2012.02.047

Keirstead, J., and Schulz, N. B. (2010). London and beyond: taking a closer look at urban energy policy.Energy Policy38,4870-4879. doi:10.1016/j.enpol.2009.07.025

Khoshsolat, S. A., Aziz, N. A., Ismail, N., and Adam, N. (2012). Repositioning of electric distribution substations using fuzzy decision making. Energy Proc. 14, 476-482. doi:10.1016/j.egypro.2011.12.961

Koch, A. (2009). "Energy balance of urban quarters for the development of energy efficiency and management strategies," in Proc. 5th Urban Res. Symp.-Cities Clim. Change Responding Urgent Agenda, Marseille, 28-30.

Kontu, K., Rinne, S., Olkkonen, V., Lahdelma, R., and Salminen, P. (2015). Multicriteria evaluation of heating choices for a new sustainable residential area. Energy Build. 93, 169-179. doi:10.1016/j.enbuild.2015.02.003

Koo, D.-H., and Ariaratnam, S. T. (2008). Application of a sustainability model for assessing water main replacement options. J. Constr. Eng. Manag. 134, 563-574. doi:10.1061/(ASCE)0733-9364(2008)134:8(563)
Li, H.-Q., Parriaux, A., and Thalmann, P. (2013). "The way to plan a sustainable "deep city": the economic model and strategic framework," in Proceedings of the 13th World Conference of ACUUS: Advances in Underground Space Development, ACUUS 2012, Singapore, 795-806.

Lipošćak, M., Afgan, N. H., Duić, N., and da Graça Carvalho, M. (2006). Sustainability assessment of cogeneration sector development in Croatia. Energy 31, 1940-1948. doi:10.1016/j.energy.2006.01.024

Løken, E. (2007). Use of multicriteria decision analysis methods for energy planning problems. Renew. Sustain. Energy Rev. 11, 1584-1595. doi:10.1016/j. rser.2005.11.005

Ma, X. (2012). Multi-Criteria Evaluation of Optimal Signal Strategies Using Traffic Simulation and Evolutionary Algorithms. 120-127.

Ma, X., Jin, J., and Lei, W. (2014). Multi-criteria analysis of optimal signal plans using microscopic traffic models. Transp. Res. Part Transp. Environ. 32, 1-14. doi:10.1016/j.trd.2014.06.013

Macoun, T. (2005). "A sustainable transport structure as a problem of choosing intelligent indicators," in WIT Transactions on the Built Environment. Presented at the 11th International Conference on Urban Transport and the Environment in the 21st Century, Urban Transport 2005 (Algarve; Portugal: WIT Press), 313-321.

Madadian, E., Amiri, L., and Abdoli, M. A. (2013). Application of analytic hierarchy process and multicriteria decision analysis on waste management: a case study in Iran. Environ. Prog. Sustain. Energy 32, 810-817. doi:10.1002/ep. 11695

Makkonen, S. (2005). Decision Modelling Tools for Utilities in the Deregulated Energy Market. Helsinki: Helsinki University of Technology.

Malczewski, J., and Rinner, C. (eds) (2015). Multicriteria Decision Analysis in Geographic Information Science.

Mardani, A., Jusoh, A., Nor, K. M., Khalifah, Z., Zakwan, N., and Valipour, A. (2015). Multiple criteria decision-making techniques and their applications - a review of the literature from 2000 to 2014. Econ. Res. Ekon Istraživanja 28, 516-571. doi:10.1080/1331677X.2015.1075139

Massara, V. M., and Udaeta, M. E. M. (2010). Multi-criteria evaluation of the expansion of natural gas distribution network by the urban dynamics. J. Urban Environ. Eng. 4, 55-62. doi:10.4090/juee.2010.v4n2.055062

Medineckiene, M., and Björk, F. (2011). Owner preferences regarding renovation measures - the demonstration of using multi-criteria decision making. J. Civ. Eng. Manag. 17, 284-295. doi:10.3846/13923730.2011.582380

Meney, K., and Pantelic, L. (2015). Novel decision model for delivering sustainable infrastructure solutions - an Australian case study. Int. J. Sustain. Dev. Plan. 10 544-561. doi:10.2495/SDP-V10-N4-544-561

Mirakyan, A., and De Guio, R. (2013a). Integrated energy planning in cities and territories: a review of methods and tools. Renew. Sustain. Energy Rev. 22, 289-297. doi:10.1016/j.rser.2013.01.033

Mirakyan, A., and De Guio, R. (2014). A methodology in innovative support of the integrated energy planning preparation and orientation phase. Energy 78 , 916-927. doi:10.1016/j.energy.2014.10.089

Mirakyan, A., and De Guio, R. (2015). Three Domain Modelling and Uncertainty Analysis: Applications in Long Range Infrastructure Planning. Cham: Springer International Publishing.

Mirakyan, A., and De Guio, R. (2013b). "Incorporating uncertainties in current integrated city and territory energy planning studies, main requirements," in 26th European Conference on Operational Research, Rome. Avaliable at: http://www. euro-online.org/conf/euro26/slot?day=W\&time $=\mathrm{A} \&$ track $=54$

Nigim, K., Munier, N., and Green, J. (2004). Pre-feasibility MCDM tools to aid communities in prioritizing local viable renewable energy sources. Renew. Energy 29, 1775-1791. doi:10.1016/j.renene.2004.02.012

Nigim, K., Reiser, H., and Luiken, M. (2009). "Alternatives prioritization tool for sustainable urban energy management," in TIC-STH'09: 2009 IEEE Toronto International Conference - Science and Technology for Humanity, 962-966.

Nijkamp, P., Rietveld, P., and Voogd, H. (1990). Multicriteria Evaluation in Physical Planning. Netherlands: Elsevier.

Nixon, J. D., Dey, P. K., Davies, P. A., Sagi, S., and Berry, R. F. (2014). Supply chain optimisation of pyrolysis plant deployment using goal programming. Energy 68 , 262-271. doi:10.1016/j.energy.2014.02.058

Nowak, D., Bortz, M., and Roclawski, H. (2015). Decision support for the design and operation of water supply systems. Proc. Eng. 119, 442-449. doi:10.1016/j. proeng.2015.08.852 
O'Brien, E. A. (2003). Human values and their importance to the development of forestry policy in Britain: a literature review. Forestry 76, 3-17. doi:10.1093/ forestry/76.1.3

Odyssee-Mure. (2015). Energy Efficiency Trends and Policies in the Household and Tertiary Sectors. Brussels: ADEME.

Oxford Dictionary of English. (2005). Synthesis. Oxf. Dict. Engl.

Öztürk, S. (2015). Determining management strategies for the Sarikum Nature Protection Area. Environ. Monit. Assess. 187. doi:10.1007/s10661-015-4302-3

Packham, I. S. J., Rafiq, M. Y., Borthwick, M. F., and Denham, S. L. (2005). Interactive visualisation for decision support and evaluation of robustness-in theory and in practice. Adv. Eng. Inform. 19, 263-280. doi:10.1016/j.aei.2005.07.006

Pedrycz, W., Ekel, P., and Parreiras, R. (eds) (2011). Fuzzy Multicriteria DecisionMaking: Models, Methods and Applications.

Pérez-Fortes, M., Laínez-Aguirre, J. M., Arranz-Piera, P., Velo, E., and Puigjaner, L. (2012). Design of regional and sustainable bio-based networks for electricity generation using a multi-objective MILP approach. Energy 44, 79-95. doi:10.1016/j.energy.2012.01.033

Petersen, J.-P. (2016). Optimization of Energy Planning Strategies in Municipalities: Are Community Energy Profiles the Key to a Higher Implementation Rate of Renewable Energies? Lyngby: Technical University of Denmark.

Phdungsilp, A. (2010). Integrated energy and carbon modeling with a decision support system: policy scenarios for low-carbon city development in Bangkok. Energy Policy 38, 4808-4817. doi:10.1016/j.enpol.2009.10.026

Pohekar, S. D., and Ramachandran, M. (2004). Application of multi-criteria decision making to sustainable energy planning-a review. Renew. Sustain. Energy Rev. 8, 365-381. doi:10.1016/j.rser.2003.12.007

Polatidis, H., Haralambopoulos, D. A., Munda, G., and Vreeker, R. (2006). Selecting an appropriate multi-criteria decision analysis technique for renewable energy planning. Energy Sources Part B Econ. Plan. Policy 1, 181-193. doi:10.1080/009083190881607

Prasad, R. D., Bansal, R. C., and Raturi, A. (2014). Multi-faceted energy planning: a review. Renew. Sustain. Energy Rev. 38, 686-699. doi:10.1016/j.rser.2014.07.021

Rager, J., Dorsaz, C., and Maréchal, F. (2013). ECOS: Integrated and Practical Energy Planning for New Districts.

Ratti, C., Baker, N., and Steemers, K. (2005). Energy consumption and urban texture. Energy Build. 37, 762-776. doi:10.1016/j.enbuild.2004.10.010

Reza, B., Sadiq, R., and Hewage, K. (2011). Sustainability assessment of flooring systems in the city of Tehran: an AHP-based life cycle analysis. Constr. Build. Mater. 25, 2053-2066. doi:10.1016/j.conbuildmat.2010.11.041

Ribau, J. P., Sousa, J. M. C., and Silva, C. M. (2015). Reducing the carbon footprint of urban bus fleets using multi-objective optimization. Energy 93, 1089-1104. doi:10.1016/j.energy.2015.09.112

Rittel, H. W. J., and Webber, M. M. (1973). Dilemmas in a general theory of planning. Policy Sci. 4, 155-169. doi:10.1007/BF01405730

Rochas, C., Kuznecova, T., and Romagnoli, F. (2015). The concept of the system resilience within the infrastructure dimension: application to a Latvian case. J. Clean. Prod. 88, 358-368. doi:10.1016/j.jclepro.2014.04.081

Roy, B. (1996). Multicriteria Methodology for Decision Aiding, Vol. 12. Dordrecht: Kluwer Academic Publishers.

Savic, D. (2002). "Single-objective vs. multiobjective optimisation for integrated decision support," in Proc. 1st Bienn. Meet. Int. Environ. Model. Softw. Soc, Vol. 1 (Lugano, Switzerland), 7-12.

Scherrer, F. (2008). La planification spatiale entre stratégies territoriales et politiques urbaines: quelles évolutions pour la planification urbaine en Europe? Lyon: UMR 5600 - CNRS.

Sheykhdavodi, M. J., Nik, M. A. E., Bilondi, M. P., Atashi, M., and Seyedian, S. M. (2010). Mechanization planning for tillage of saffron fields using multiple criteria decision-making technique as a policy framework in Iran. Aust. J. Crop Sci. 4, 295-300.

Siebert, J., and Keeney, R. L. (2015). Creating more and better alternatives for decisions using objectives. Oper. Res. 63, 1144-1158. doi:10.1287/opre.2015.1411

St. Denis, G., and Parker, P. (2009). Community energy planning in Canada: the role of renewable energy. Renew. Sustain. Energy Rev. 13, 2088-2095. doi:10.1016/j. rser.2008.09.030

Strantzali, E., and Aravossis, K. (2016). Decision making in renewable energy investments: a review. Renew. Sustain. Energy Rev. 55, 885-898. doi:10.1016/j. rser.2015.11.021

Strasser, H. (2015). Implementation of Energy Strategies in Communities - From Pilot Project in Salzburg, Austria, to Urban Strategy. ASHRAE Trans, Vol. 121. Chicago: Amer. Soc. Heating, Ref. Air-Conditoning Eng. Inc., 176-184.
Teriman, S., Yigitcanlar, T., and Mayere, S. (2010). "Sustainable urban development: an integrated framework for urban planning and development," in Rethinking Sustainable Development: Urban Management, Engineering, and Design (Australia: IGI Global, Queensland University of Technology), 1-14.

Thery, R., and Zarate, P. (2009). Energy planning: a multi-level and multicriteria decision making structure proposal. Cent. Eur. J. Oper. Res. 17, 265-274. doi:10.1007/s10100-009-0091-5

Tzeng, G.-H., Lin, C.-W., and Opricovic, S. (2005). Multi-criteria analysis of alternative-fuel buses for public transportation. Energy Policy 33, 1373-1383. doi:10.1016/j.enpol.2003.12.014

UNCED. (1992). "Agenda 21," in The United Nations Conference on Environment and Development, Earth Summit; Rio de Janeiro, 3-14, 1992.

UN-Habitat. (2009). Global Report on Human Settlements 2009: Planning Sustainable Cities. London: Earthscan.

UP-RES. (2011). Competence and Training Needs Analysis for RES H/C Integration in Urban Planning, Results of Comparative Studies and Survey.

Vadiati, M., Kabiri, M., Nekouei, F., and Ebrahimi, A. R. (2012). A New Solution for Space Saving of Substations in Tehran Regional Electric Company.

Vafaeipour, M., Hashemkhani Zolfani, S., Morshed Varzandeh, M. H., Derakhti, A., and Keshavarz Eshkalag, M. (2014). Assessment of regions priority for implementation of solar projects in Iran: new application of a hybrid multi-criteria decision making approach. Energy Convers. Manag. 86, 653-663. doi:10.1016/j. enconman.2014.05.083

Van Haaren, R., and Fthenakis, V. (2011). GIS-based wind farm site selection using spatial multi-criteria analysis (SMCA): evaluating the case for New York State. Renew. Sustain. Energy Rev. 15, 3332-3340. doi:10.1016/j.rser.2011.04.010

Videla, S., Chamy, R., Navarrete, E., and Lema, J. M. (1990). Design and operation of anaerobic digesters using multi-objective optimization criteria. J. Chem. Technol. Biotechnol. 49, 223-231. doi:10.1002/jctb.280490303

Vučićević, B., Jovanović, M., Afgan, N., and Turanjanin, V. (2014). Assessing the sustainability of the energy use of residential buildings in Belgrade through multi-criteria analysis. Energy Build. 69, 51-61. doi:10.1016/j. enbuild.2013.10.022

Wachs, M. (2001). Forecasting versus envisioning: a new window on the future. J. Am. Plann. Assoc. 67, 367-372. doi:10.1080/01944360108976245

Wang, J.-J., Jing, Y.-Y., Zhang, C.-F., and Zhao, J.-H. (2009). Review on multi-criteria decision analysis aid in sustainable energy decision-making. Renew. Sustain. Energy Rev. 13, 2263-2278. doi:10.1016/j.rser.2009.06.021

Wang, L., Xu, L., and Song, H. (2011). Environmental performance evaluation of Beijing's energy use planning. Energy Policy 39, 3483-3495. doi:10.1016/j. enpol.2011.03.047

Wierzbicki, A., Makowski, M., and Wessels, J. (2000). Model-Based Decision Support Methodology with Environmental Applications. The Netherlands: Kluwer Academic Publishers.

Wu, W., Simpson, A. R., Maier, H. R., and Marchi, A. (2012). Incorporation of variable-speed pumping in multiobjective genetic algorithm optimization of the design of water transmission systems. J. Water Resour. Plan. Manag. 138, 543-552. doi:10.1061/(ASCE)WR.1943-5452.0000195

Yedla, S., and Shrestha, R. M. (2003). Multi-criteria approach for the selection of alternative options for environmentally sustainable transport system in Delhi. Transp. Res. Part Policy Pract. 37, 717-729. doi:10.1016/S0965-8564(03) 00027-2

Yokoyama, R., and Ito, K. (1995). Multi-objective optimization in unit sizing of a gas turbine cogeneration plant. J. Eng. Gas Turbines Power 117, 53-59. doi: $10.1115 / 1.2812781$

Zanon, B., and Verones, S. (2013). Climate change, urban energy and planning practices: Italian experiences of innovation in land management tools. Land use policy 32, 343-355. doi:10.1016/j.landusepol.2012.11.009

Zhang, S., Pan, W., and Kumaraswamy, M. (2014). A multi-criteria decision framework for the selection of low carbon building measures for office buildings in hong kong. Int. J. Energy Sect. Manag. 8, 456-476. doi:10.1108/ IJESM-03-2014-0005

Zheng, J. H., Chen, J. J., Wu, Q. H., and Jing, Z. X. (2015). Multi-objective optimization and decision making for power dispatch of a large-scale integrated energy system with distributed DHCs embedded. Appl. Energy 154, 369-379. doi:10.1016/j.apenergy.2015.05.023

Zhou, P., Ang, B. W., and Poh, K. L. (2006). Decision analysis in energy and environmental modeling: an update. Energy 31, 2604-2622. doi:10.1016/j. energy.2005.10.023 
Ziemele, J., Vigants, G., Vitolins, V., Blumberga, D., and Veidenbergs, I. (2014). District heating systems performance analyses. Heat energy tariff. Environ. Clim. Technol. 13, 32-43. doi:10.2478/rtuect-2014-0005

Conflict of Interest Statement: The authors declare that the research was conducted in the absence of any commercial or financial relationships that could be construed as a potential conflict of interest.
Copyright (C) 2017 Cajot, Mirakyan, Koch and Maréchal. This is an open-access article distributed under the terms of the Creative Commons Attribution License (CC BY). The use, distribution or reproduction in other forums is permitted, provided the original author(s) or licensor are credited and that the original publication in this journal is cited, in accordance with accepted academic practice. No use, distribution or reproduction is permitted which does not comply with these terms. 